\title{
Subseasonal intensity variation of the South Asian high in relationship to diabatic heating: observation and CMIP5 models
}

\author{
Wei Shang ${ }^{1} \cdot$ Xuejuan Ren $^{1}$ (D) $\cdot$ Bo Huang ${ }^{2}$ - Ulrich Cubasch ${ }^{3} \cdot$ Xiu-Qun Yang $^{1}$
}

Received: 23 October 2017 / Accepted: 15 May 2018 / Published online: 30 May 2018

(c) The Author(s) 2018

\begin{abstract}
This study investigates the subseasonal intensity variation of South Asian high (SAH) and the dynamic linkage with precipitation induced diabatic heating during the summer of 1979-2005, based on the observation and 18 models from the Coupled Model Intercomparison Project (CMIP5). The SAH's intensity variation with a period of approximately 10-36 days is identified both in the observation and 18 models, by performing an empirical orthogonal function (EOF) analysis on the standardized subseasonal anomalies in geopotential height at $100 \mathrm{hPa}$ over the SAH's main body region. With the observed strengthening of the $\mathrm{SAH}$, an enhanced rainfall belt between $70^{\circ}-120^{\circ} \mathrm{E}$ migrates northward from the equatorial region. The northward propagating rainfall belt occupies almost the whole Indian subcontinent, Indochina Peninsula and subtropical east Asian regions between $20^{\circ}-40^{\circ} \mathrm{N}$ when the SAH reaches the strongest. The relative vorticity diagnosis reveals the dynamical linkage between the subseasonal SAH's intensity variation and the precipitation anomalies over the Asian monsoon region: (1) The observed northward propagating rainfall band forms a horizontal gradient of diabatic heating, favoring an enhancement of the SAH over its southern part; (2) When the rainfall band approaches the regions of South and East Asia between $20^{\circ}-40^{\circ} \mathrm{N}$, the increased vertical gradient of diabatic heating in the upper level contributes significantly to the intensification of the SAH; (3) The horizontal advection process favors the westward expansion of the SAH. The observation-to-model comparisons indicate that the model's capacity to reproduce the SAH's intensity variation is highly associated with simulations of the anomalous rainfall band and its northward propagation. A realistic reproduction of precipitation anomalies is fundamental to simulating the dynamical processes related to diabatic heating, and thus the simulation of the SAH's subseasonal intensity variation.
\end{abstract}

Keywords South Asian high $\cdot$ CMIP5 $\cdot$ Subseasonal intensity variation $\cdot$ Diabatic heating

\section{Introduction}

The South Asian high (SAH) is a planetary-scale anticyclonic circulation in the upper troposphere, with its main body zonally elongated over the Iranian Plateau (IP)-Tibetan Plateau (TP) and the surrounding areas during summer

Xuejuan Ren

renxuej@nju.edu.cn

1 CMA-NJU Joint Laboratory for Climate Prediction Studies, School of Atmospheric Sciences, Nanjing University, Nanjing 210023, People's Republic of China

2 Industrial Ecology Programme, Department of Energy and Process Engineering, Norwegian University of Science and Technology, Trondheim, Norway

3 Institute of Meteorology, Freie Universität Berlin, Berlin, Germany
(Mason and Anderson 1963; Tao and Zhu 1964; Krishnamurti 1973). As a member of the Asian summer monsoon system, the SAH's spatiotemporal variability and impacts on the weather and climate over Asia and beyond have been investigated (Zhang et al. 2002, 2005, 2016; Liu et al. 2004, 2007, 2013; Duan and Wu 2005; Randel and Park 2006; Zarrin et al. 2010; Huang et al. 2011; Jiang et al. 2011; Qu and Huang 2012; Wei et al. 2014; Yang et al. 2014; Ren et al. 2015; Wu et al. 2015; Chen and Zhai 2016; Shi and Qian 2016; Yang and Li 2016). Especially, variations of the SAH on subseasonal time scale have attracted more attention in recent years. Because some high-impact events (e.g. persistent heavy rainfall or long-lived heat wave) are often induced by anomalies in atmospheric circulation and water vapor transport accompanied by the SAH's subseasonal variations (Ren et al. 2015; Yang et al. 2017; Chen and Zhai 2016; Ge et al. 2017). 
Previous studies (Tao and Zhu 1964; Zhang et al. 2002; Jia and Yang 2013; Ren et al. 2015; Yang and Li 2016) have identified two dominant modes of the SAH's variations on subseasonal time scale. One mode demonstrates zonal movement of the SAH's main body (denoted as "zonal oscillation"). Another one depicts the intensity variation of the SAH's main body (hereafter "intensity variation"). The SAH's zonal oscillation around its climatology position for periods of weeks were firstly revealed by Mason and Anderson (1963), and Tao and Zhu (1964). Zhang et al. (2002) suggested the bimodality of the SAH at $100 \mathrm{hPa}$ and identified them as the Iranian pattern and the Tibetan pattern, respectively. Further investigations have studied the features of subseasonal zonal shift of the SAH and its connection with precipitation and diabatic heating over eastern Asia (Ren et al. 2015; Shi and Qian 2016; Yang and Li 2016). Other literature mentioned about the SAH's subseasonal intensity variation. For example, Jia and Yang (2013) demonstrated that the northwestward propagation of the quasi-biweekly oscillation over the western North Pacific is accompanied by the strengthening of SAH, which contributes to the upper level divergence pattern over the subtropical east Asian region. Yang et al. (2017) suggested that the SAH is enhanced with eastward and westward extensions when the quasi-biweekly oscillation in the eastern TP summer precipitation transits from its dry to wet phase. Compared to the studies about the SAH's zonal oscillation, our understanding of characteristics and mechanisms for SAH's intensity variation on subseasonal time scale is incomplete. This makes up the core subject of the present study.

The SAH is considered as a thermal-driven circulation (Jin and Hoskins 1995; Liu et al. 2004; Lin 2009). Diabatic heating induced by precipitation is an important dynamical factor responsible for the SAH's variations (Liu et al. 2004, 2007, 2013; Ren et al. 2015; Chen and Zhai 2016; Wang and Ge 2016; Ge et al. 2017). Ren et al. (2015) suggested that a north-south dipolar structure of the condensation heating/ rainfall over eastern Asia performed a positive feedback in the SAH's subseasonal zonal oscillation. Similar relationship between condensation heating over eastern Asia and the zonal oscillation of the SAH were also advocated by Yang and Li (2016), Chen and Zhai (2016) and Wang and Ge (2016). The strengthening/weakening of SAH is also accompanied by precipitation anomalies over monsoon region (Jia and Yang 2013; Yang et al. 2017). The corresponding change in diabatic heating should be a no-negligible factor responsible for the SAH's subseasonal intensity variation. The present study focuses on this factor. We intend to reveal the role of precipitation induced diabatic heating on the SAH's intensity variation through performing a diagnosis on relative vorticity.

Besides, we also evaluate the model performances in reproducing the features of the SAH's subseasonal intensity variation and the corresponding dynamical mechanisms. The World Climate Research Programme (WCRP) Working Group on Coupled Modelling (WGCM) has employed the phase 5 of Coupled Model Intercomparison Project (CMIP5) since September 2008 (Taylor et al. 2012). Evaluating the ability of the CMIP5 models in simulating the Asian summer monsoon has been carried out (Duan et al. 2013; Huang et al. 2013; Cherchi et al. 2014; Lee and Wang 2014; Freychet et al. 2015; Gao et al. 2015; Sooraj et al. 2016; Li et al. 2017). Some studies have assessed the capacity of climate models in simulating the SAH's climatology and its variations. Xue et al. (2017) studied the climatology and interannual variations of the SAH in 38 CMIP5 models. They pointed out that two-thirds of these models can simulate the observed relationship between the El Niño-Southern Oscillation (ENSO) and the SAH. Qu and Huang (2015) evaluated the performance of CMIP5 models in reproducing the decadal relationship between the SAH and sea surface temperature in the tropical Indian Ocean. The above investigations assessed the SAH's interannual to decadal variations simulated by the CMIP5 models. The present evaluation focuses on the subseasonal intensity variation of the SAH.

The paper is organized as follows. Section 2 introduces the datasets, CMIP5 models and analysis methods. Section3 presents the features of climatology and the subseasonal intensity variation of the SAH, and investigates the relationship between precipitation and the SAH in the observation and CMIP5 models. Section 4 reveals the corresponding dynamical mechanism. A summary and discussion is shown in Sect. 5.

\section{Datasets and methods}

\subsection{Datasets}

The datasets used include (1) daily reanalysis data on a $1^{\circ} \times 1^{\circ}$ horizontal resolution in 1979-2005 derived from the European Center for Medium-Range Weather Forecasts (ECMWF) (ERA-Interim, Dee et al. 2011), (2) daily mean outgoing longwave radiation (OLR) data on a $2.5^{\circ} \times 2.5^{\circ}$ grid from the National Oceanic and Atmospheric Administration (NOAA) (Liebmann and Smith 1996) for 1979-2005, and (3) gauge-based analysis of global daily precipitation data from NOAA Climate Prediction Center (CPC) for the period $1979-2005$ on $0.5^{\circ} \times 0.5^{\circ}$ horizontal resolution. Further details for the precipitation dataset can be found in Xie et al. (2007) and Chen et al. (2008). The observational and reanalysis datasets are called "observation" in the present study.

The historical experiments for daily mean fields of 18 CMIP5 models from 1979 to 2005 are used in this study (Taylor et al. 2012). Table 1 shows the detail information, 
Table 1 Information of CMIP5 climate models

\begin{tabular}{|c|c|c|}
\hline Models name & Institute/country & Resolution \\
\hline ACCESS1-0 & $\begin{array}{l}\text { Commonwealth Scientific and Industrial Research Organization (CSIRO) and Bureau of Meteorology } \\
(\mathrm{BOM}) / \text { Australia }\end{array}$ & $192 \times 144$ \\
\hline ACCESS1-3 & CSIRO and BOM/Australia & $192 \times 144$ \\
\hline BNU-ESM & Beijing Normal University/China & $128 \times 64$ \\
\hline CanESM2 & Canadian Center for Climate Modeling and Analysis/Canada & $128 \times 64$ \\
\hline FGOALS-g2 & $\begin{array}{l}\text { State Key Laboratory of Numerical Modeling for Atmospheric Sciences and Geophysical Fluid Dynamics } \\
\text { (LASG)/China }\end{array}$ & $128 \times 60$ \\
\hline GFDL-CM3 & National Oceanic and Atmospheric Administration (NOAA) GFDL/United States & $144 \times 90$ \\
\hline GFDL-ESM2G & NOAA/GFDL/United States & $144 \times 90$ \\
\hline HadGEM2-CC & Met Office Hadley Centre (MOHC)/United Kingdom & $192 \times 144$ \\
\hline HadGEM2-ES & MOHC/United Kingdom & $192 \times 144$ \\
\hline IPSL-CM5A-LR & Institute Pierre Simon Laplace/France & $96 \times 96$ \\
\hline IPSL-CM5A-MR & Institute Pierre Simon Laplace/France & $144 \times 143$ \\
\hline MIROC5 & $\begin{array}{l}\text { University of Tokyo, National Institute for Environmental Studies and Japan Agency for Marine-Earth Sci- } \\
\text { ence and Technology/Japan }\end{array}$ & $256 \times 128$ \\
\hline MIROC-ESM-CHEM & $\begin{array}{l}\text { University of Tokyo, National Institute for Environmental Studies and Japan Agency for Marine-Earth Sci- } \\
\text { ence and Technology/Japan }\end{array}$ & $128 \times 64$ \\
\hline MPI-ESM-LR & Max-Planck Institute for Meteorology (MPI-M)/Germany & $192 \times 96$ \\
\hline MPI-ESM-MR & MPI-M/Germany & $192 \times 96$ \\
\hline MRI-CGCM3 & Meteorological Research Institute/Japan & $320 \times 160$ \\
\hline MRI-ESM1 & Meteorological Research Institute/Japan & $320 \times 160$ \\
\hline NorESM1-M & Norwegian Climate Center (NCC)/Norway & $144 \times 96$ \\
\hline
\end{tabular}

including the institutes, horizontal resolutions of these models. Given the large volume of data, only one run from each model and experiment was used in this study. The model outputs are interpolated onto $1^{\circ} \times 1^{\circ}$ resolution to match the ERA-Interim reanalysis data. More information about the 18 CMIP5 models can be referred to http://cmip-pcmdi .llnl.gov/cmip5/.

\subsection{Extracting subseasonal daily anomalies and the SAH's subsesonal intensity variation}

We use the method adopted by Krishnamurthy and Shukla (2000) and Ren et al. (2015) to extract the subseasonal daily anomalies both for observation and for model data for all the variables. The process is as follows. First, a 5-day running mean is preformed to remove the high-frequency fluctuations in the daily data, and then remove the daily climatology to get daily anomalies, finally, remove the interannual signal by subtracting seasonal anomaly.

The amplitudes of $100 \mathrm{hPa}$ geopotential height (Z100) anomalies are increased rapidly from the tropical to extratropical latitudes. To avoid the variance of the EOF being dominated by the signals in the middle latitudes, the EOF analysis is performed on standardized subseasonal anomalies of Z100 over the SAH's main body region during summer (June, July and August) of 1979-2005 (27 ×92=2484 days in total). We also perform the latitudinal weight before EOF analysis and the EOF results are similar. The main body region $\left(20^{\circ}-40^{\circ} \mathrm{N}, 35^{\circ}-110^{\circ} \mathrm{E}\right)$ covers the climatological $16,750 \mathrm{gpm}$ contour line of the $\mathrm{SAH}$ at $100 \mathrm{hPa}$ (Fig. 1a). A power spectrum analysis (Gilman et al. 1963) is used to identify the dominant periodicity on the principal components of EOF.

The observed first EOF mode (EOF1) demonstrates a monopole pattern centered over the IP-western TP. This mode indicates the SAH's intensity variation on subseasonal time scale. The observed second EOF mode displays a positive center of anomalous Z100 over East Asia and a negative one over the IP. It represents the subseasonal zonal oscillation of the SAH, which has been intensively studied (Zhang et al. 2002; Ren et al. 2015; Shi and Qian 2016; Yang and Li 2016; Chen and Zhai 2016). We focus on the EOF1 in this study. Time-lagged regressions of the observed subseasonal variables on the normalized first principal components of EOF (observed normalized PC1) are calculated. The same process is then done on each of the 18 models' simulation. The time-lagged regression is used. Day 0 is simultaneous in regression. The simultaneously regression fields can show the anomalous pattern when the SAH gets it strongest stage (the positive peak of normalized PC1). The lead-lag regression can demonstrate the evolution pattern of anomalies accompanied by the evolution of the SAH. A negative lag day (a positive lag day) is obtained by shifting backward (forward) the number of the leading (lag) days. 

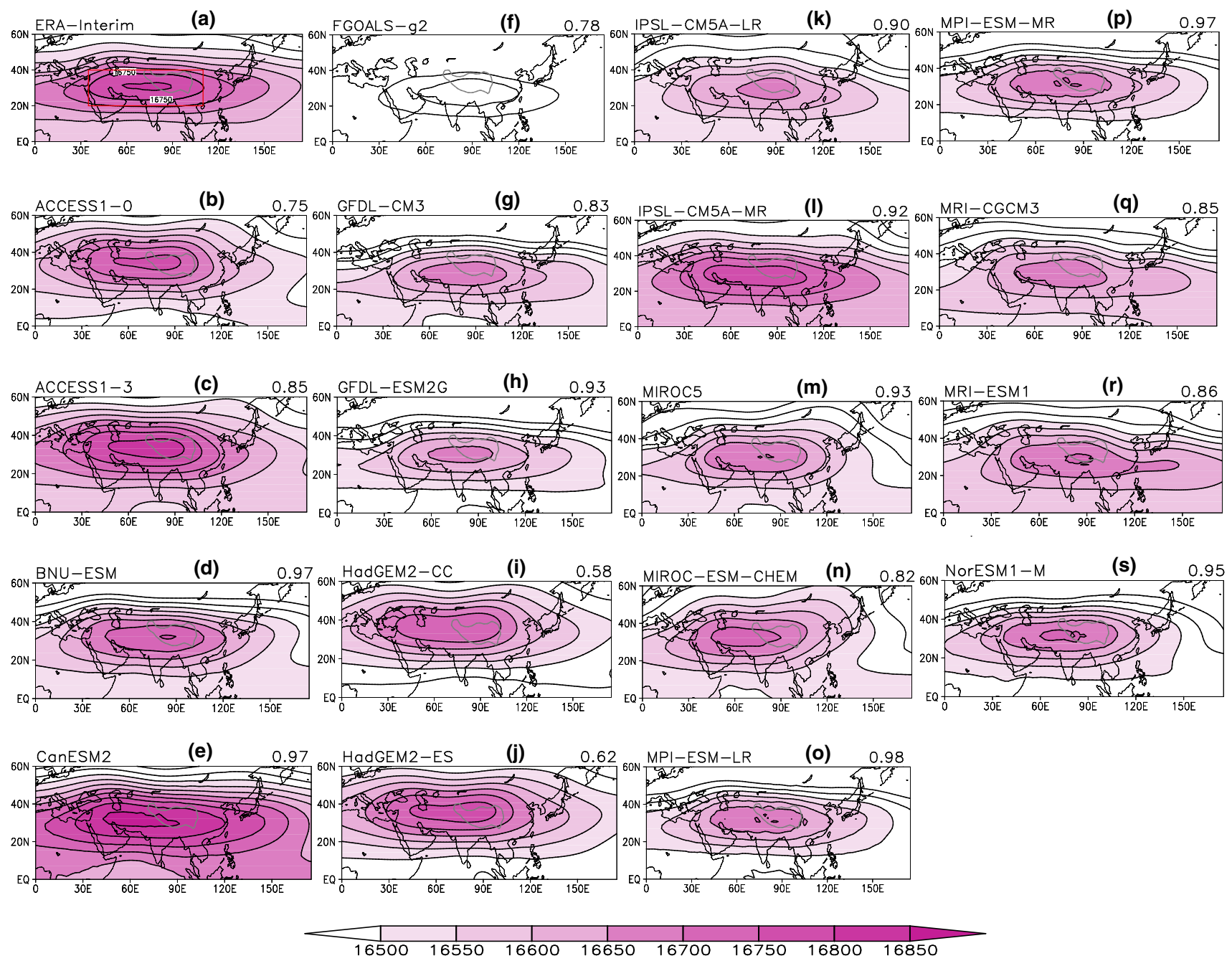

Fig. 1 Climatological summer (June, July and August) fields of Z100 (contour and shaded with interval of $50 \mathrm{gpm}$ ) during 1979-2005 for a ERA-Interim and $\mathbf{b}-\mathbf{s}$ results of the 18 CMIP5 models. The spatial correlation coefficients between the ERA-interim and individual

\subsection{Diagnosis on relative vorticity equation}

Following the Ertel potential vorticity equation (Ertel 1942; Hoskins et al. 1985), the relatively vorticity equation is expressed as (Wu and Liu 1998; Wu et al. 1999; Liu et al. 2001, 2004, 2013).

$\frac{\partial \zeta}{\partial t}=-\mathrm{V}_{h} \cdot \nabla_{h} \zeta-\beta v-(f+\zeta) \nabla_{h} \cdot \mathrm{V}_{h}+\frac{f+\zeta}{\theta_{z}} \frac{\partial Q_{1}}{\partial z}+S$,

$S=-\frac{1}{\theta_{z}} \frac{\partial v}{\partial z} \frac{\partial Q_{1}}{\partial x}+\frac{1}{\theta_{z}} \frac{\partial u}{\partial z} \frac{\partial Q_{1}}{\partial y}$,

where $\zeta$ is relative vorticity, $V_{h}=(u, v)$ the horizontal wind, $V_{h}$ the horizontal gradient operator, $f$ the planetary vorticity, and $\theta_{z}$ and $Q_{1}$ are the static stability and diabatic
CMIP5 models over the region of $15^{\circ}-45^{\circ} \mathrm{N}, 10^{\circ}-140^{\circ} \mathrm{E}$ are shown at each of the top-right corners. The red box in a denotes the region for EOF analysis in Fig. 2. The grey line in each is the outline of the Tibetan Plateau

heating, respectively. According to Eq. (1), the changes of $\zeta$ are contributed by the following processes: the horizontal advection of relative vorticity, $\beta$ effect, divergence of atmospheric circulation, and vorticity sources induced by vertical and horizontal gradients of $Q_{1}$.

Diabatic heating $Q_{1}$ (also known as apparent heating source) and apparent moisture sink $Q_{2}$ and their vertically integrated values $\left\langle Q_{1}\right\rangle$ and $\left\langle Q_{2}\right\rangle$ are calculated based on the following formulas (Yanai et al. 1973; Luo and Yanai 1984)

$Q_{1}=\frac{\partial T}{\partial t}+\mathrm{V}_{h} \cdot \nabla_{h} T+\omega\left(\frac{\partial T}{\partial p}-\frac{R T}{c_{p} P}\right)$

$Q_{2}=-L\left[\frac{\partial q}{\partial t}+\mathrm{V}_{h} \cdot \nabla_{h} q+\left(\frac{P}{P_{0}}\right)^{k} \omega \frac{\partial q}{\partial t}\right]$, 


$$
\left\langle Q_{1}\right\rangle=\frac{1}{g} \int_{p_{t}}^{p_{s}} Q_{1} d p,
$$

$$
\left\langle Q_{2}\right\rangle=\frac{1}{g} \int_{P_{t}}^{P_{s}} Q_{2} d p,
$$

where $T$ is the air temperature; $q$ is the water vapor, $\omega$ is the vertical velocity in pressure $(P)$ coordinates; $k=\frac{R}{c_{p}}, R$ and $c_{p}$ are the gas constant and specific heat at constant pressure of dry air, respectively; $L$ is the latent heat of condensation; $P_{0}=1000 \mathrm{hPa} . \mathrm{g}$ is the gravitational acceleration; $P_{t}$ and $P_{s}$ are tropopause pressure and surface pressure, respectively. The components of diabatic heating $Q_{1}$ include: radiative heating, turbulent sensible heating at the earth surface, and condensation latent heating induced by precipitation. The apparent moisture $\operatorname{sink} Q_{2}$ is mainly related to the condensation latent heating. A similar pattern of $\left\langle Q_{1}\right\rangle$ and $\left\langle Q_{2}\right\rangle$ over summer monsoon region indicates that condensational heating induced by precipitation is the major component of diabatic heating (Yanai and Tomita 1998; Jin et al. 2013).

A variable is decomposed into its time mean (denoted with an overbar) and subseasonal (denoted with a prime), and non-subseasonal components (Zhang and Ling 2012; Ren et al. 2015). The horizontal advection of relative vorticity and the two vorticity generation terms in Eq. (1) which contribute to the subseasonal anomaly of local vorticity change $\left(\frac{\partial \zeta^{\prime}}{\partial t}\right)$, can be expressed as follows:

$\left(\frac{\partial \zeta^{\prime}}{\partial t}\right) a d v=-\left(\bar{u} \frac{\partial \zeta^{\prime}}{\partial x}+\bar{v} \frac{\partial \zeta^{\prime}}{\partial y}\right)-\left(u^{\prime} \frac{\partial \bar{\zeta}}{\partial x}+v^{\prime} \frac{\partial \bar{\zeta}}{\partial y}\right)+$ residue

$\left(\frac{\partial \zeta^{\prime}}{\partial t}\right) Q_{1 \_} z=\frac{1}{\bar{\theta}_{z}}(f+\bar{\zeta}) \frac{\partial Q_{1}^{\prime}}{\partial z}+\frac{1}{\bar{\theta}_{z}} \zeta^{\prime} \frac{\partial \overline{Q_{1}}}{\partial z}+$ residue,

$$
\begin{aligned}
\left(\frac{\partial \zeta^{\prime}}{\partial t}\right) S= & \frac{1}{\bar{\theta}_{z}}\left(\frac{\partial \bar{u}}{\partial z} \frac{\partial Q_{1}^{\prime}}{\partial y}-\frac{\partial \bar{v}}{\partial z} \frac{\partial Q_{1}^{\prime}}{\partial x}\right) \\
& +\frac{1}{\bar{\theta}_{z}}\left(\frac{\partial u^{\prime}}{\partial z} \frac{\partial \overline{Q_{1}}}{\partial y}-\frac{\partial v^{\prime}}{\partial z} \frac{\partial \overline{Q_{1}}}{\partial x}\right)+\text { residue }
\end{aligned}
$$

Where residue terms represent the contributions from nonlinear interaction between subseasonal and non-subseasonal components. The residue terms in (7)-(9), $\beta$ effect, and divergence term in (1) are much smaller than the others and thus ignored hereinafter.

\section{Characteristics of subseasonal intensity variation of SAH}

\subsection{Subseasonal intensity variation of the SAH}

Before showing the EOF results, we depict the observed and simulated climatological summer mean fields of Z100 for 1979-2005. The observed SAH is located over the IP-TP and its surrounding areas, with its center value slightly higher than 16,800 gpm (Fig. 1a). The simulations by 18 CMIP 5 models reproduce the zonally elongated structure of the SAH in general (Fig. 1b-s). Among the 18 models, CanESM2 slightly overestimates the intensity of the SAH with the center higher than $16,850 \mathrm{gpm}$, while the SAH's centers of FGOALS-g2, GFDL-ESM2G, IPSL-CM5A-LR, MRI-CGCM3 are less than 16,700 gpm. Based on the pattern correlation between the observation and the 18 models, MPI-ESM-LR, BNU-ESM, CanESM2, MPI-ESM-MR and NorESM1-M show better skills on simulation of the climatological SAH. Their pattern correlation coefficients are above 0.95 . HadGEM2-CC and HadGEM2-ES produce a slightly northward center of SAH compared to the observation. Their pattern correlations are around 0.6.

The spatial pattern of the observed EOF1 is plotted in Fig. 2a. It demonstrates a monopole pattern with a center over the IP-western TP region. As mentioned earlier, this pattern exhibits the spatial structure of subseasonal intensity variation of SAH. The variance of the observed EOF1 is $43 \%$. Figure $2 \mathrm{~b}-\mathrm{s}$ depict the EOF1 patterns of each CMIP5 models. The 18 models simulate the monopole pattern to a certain extent with variances ranging from 33 to $44 \%$. We calculate the subseasonal pattern correlation coefficients $\left(\mathrm{r}_{\mathrm{EOF}}\right.$ ) between the observed EOF1 and each model's. ACCESS1-0, ACCESS1-3, BNU-ESM, HadGEM2-CC, HadGEM2-ES, MIROC-ESM-CHEM, MRI-CGCM3, and NorESM1-M reasonably reproduce a similar EOF1 pattern to the observation's with $\mathrm{r}_{\mathrm{EOF}} \geq 0.8$. Some other models show differences in the location of the monopole center, compared to the observation. For example, the anomalous centers simulated by CanESM2, GFDL-CM3, IPSL-CM5A-LR and IPSL-CM5A-MR are located slightly poleward. Their subseasonal pattern correlation coefficients $\mathrm{r}_{\mathrm{EOF}}$ are under 0.5 .

We divide the 18 models into three groups, according to the value of $\mathrm{r}_{\mathrm{EOF}}$ (1) Better-simulated group (BG) with $\mathrm{r}_{\mathrm{EOF}} \geq 0.8$, includes ACCESS1-3 (0.98), HadGEM2CC (0.96), ACCESS1-0 (0.93), HadGEM2-ES (0.93), MIROC-ESM-CHEM (0.90), BNU-ESM (0.89), MRICGCM3 (0.84), NorESM1-M (0.8). (2) General-simulated group (GG) with $\mathrm{r}_{\mathrm{EOF}}$ between 0.8 and 0.5 , includes MRIESM1 (0.72), MIROC5 (0.68), MPI-ESM-MR (0.68), 

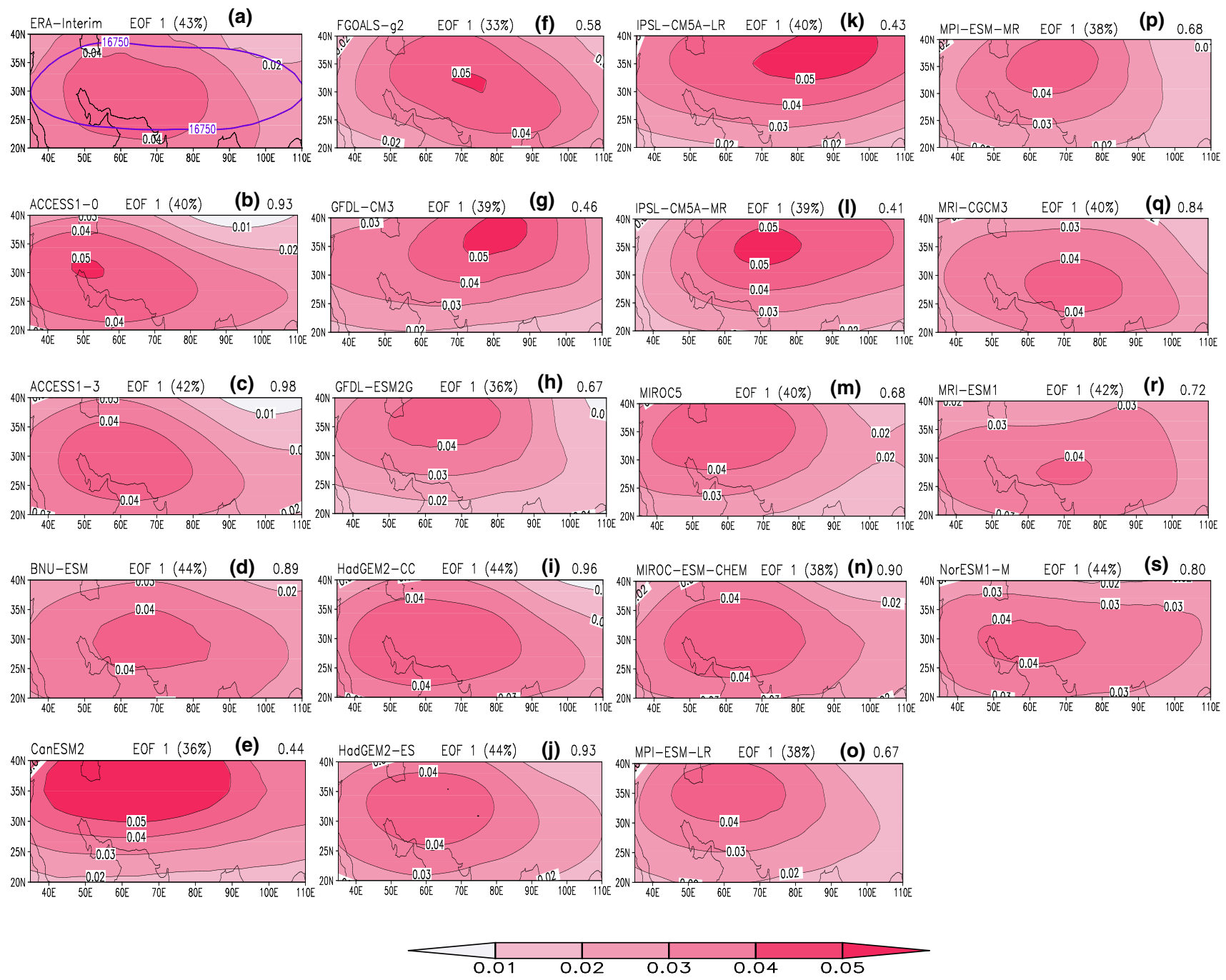

Fig. 2 Spatial pattern of the first EOF mode of normalized subseasonal anomalies of $\mathrm{Z} 100$ over the region of $20^{\circ}-40^{\circ} \mathrm{N}, 35^{\circ}-110^{\circ} \mathrm{E}$. a ERA-Interim and $\mathbf{b}-\mathbf{s}$ the results of the 18 CMIP5 models. The spatial correlation coefficients between the first EOF of the ERA-
Interim and those of the CMIP5 models $\left(\mathrm{r}_{\mathrm{EOF}}\right)$ are displayed at each of the top-right corners. The purple contour in $\mathbf{a}$ is the climatological $16,750 \mathrm{gpm}$ contour line of the $\mathrm{SAH}$ at $100 \mathrm{hPa}$

LG models, CanESM2, GFDL-CM3, IPSL-CM5A-LR and IPSL-CM5A-MR, all simulate no significant peak period.

Figure $4 \mathrm{a}-\mathrm{e}$ plot the regression of subseasonal Z100 and $100 \mathrm{hPa}$ wind field anomalies on the normalized PC1 for the observation, from days -9 to +3 with interval of 3 days. In the observation, it is seen that an anomalous high is in control of the SAH area at $100 \mathrm{hPa}$ centered over the IP-western TP and East Asia at day 0. Meanwhile, a cyclonic one exists over the Barents Sea and Novaya Zemlya poleward of the anomalous high. Such anomalous pattern is seen on day -9 with a weak amplitude. From days -6 to -3 , the anomalous high and low centers become more significant with intensified amplitudes. The above pattern matures on day 0 and fades away locally after day 0 . 
The regression of subseasonal anomalies in Z100 and $100 \mathrm{hPa}$ wind field for the three selected models, ACCESS1-3 (BG), MRI-ESM1 (GG) and IPSL-CM5AMR (LG) on each model's normalized PC1, are shown in Fig. 4f-t. In general, all the three models can simulate the anomalous anticyclonic band over the SAH's main body region. However, the simulation results show differences in the intensity of the anomalous anticyclone and its center location. ACCESS1-3 (BG, Fig. 4f-j) simulates most of the observed features of the $\mathrm{Z} 100$ anomalous circulation, especially the anomalous anticyclonic center anchored over the IP-western TP region with an amplitude close to the observation. The evolution process simulated by ACCESS1-3 from days -9 to +3 also bears resemblance with that in the observation. MRI-ESM1 (GG, Fig. 4k-o) reproduces the anomalous anticyclonic band over the SAH's main body region with slightly weaker amplitude and with the center shifting to the western part of TP compared to ACCESS1-3 and the observation. IPSL-CM5A-MR (LG, Fig. 4p-t) simulates a much weaker anomalous anticyclone over the IP-TP region from days -9 to +3 , compared to the observation, ACCESS1-3 (BG) and MRI-ESM1 (GG).

\subsection{The precipitation anomaly associated with SAH}

Figure $5 \mathrm{a}-\mathrm{d}$ plot the time-lagged regression of precipitation and OLR anomalies on PC1 for the observation. The northward propagation of the anomalous rainfall belt is seen in the observation. During the early stage of the SAH's strengthening (prior to day -6 ), positive precipitation anomalies are located between the equator and $20^{\circ} \mathrm{N}$, consistent with the local negative OLR anomalies. Increased precipitation also scatters over the regions to the east of TP, southern Korea and southern Japan. During days -6 to -4 , the area with increased rainfall expands northward to almost all over the Indian subcontinent, Indo-China Peninsula and subtropical east Asian region. When the SAH's intensity reaches its peak stage (day 0), the positive rainfall belt propagates northward furthermore covering almost the whole of south Asian and east Asian summer monsoon regions between $20^{\circ}$ and $40^{\circ} \mathrm{N}$. After day 0 , the above increased precipitation region becomes shrink, especially over the area to the east of TP.

The simulated time-lagged regression of precipitation anomalies on PC1 for the three models are shown in Fig. 5e to p. ACCESS1-3 reproduces the northward propagation of the precipitation anomalies with the strengthening of the SAH, though with a slightly stronger amplitude and weaker signals over the Indian subcontinent compared to the observation (Fig. 5e-h). MRI-ESM1 simulates the northward propagation of the precipitation anomalies in general (Fig. 5i-1). However, its zonal rainfall belt is not well organized. The simulated precipitation anomaly over the eastern Asian continent is too weak. IPSL-CM5AMR's simulations of rainfall belt and its northward propagation are much weaker, compared to the observation and the other two models' (Fig. $5 \mathrm{~m}$ to p).

We plot latitude-time section of the precipitation anomalies for the observation (Fig. 6a) and 18 models (Fig. 6b-s), averaged over $70^{\circ}-120^{\circ} \mathrm{E}$, to further demonstrate the simulated northward propagating feature of precipitation anomaly. Figure $6 \mathrm{~b}-\mathrm{s}$ are sorted according to $\mathrm{r}_{\mathrm{EOF}}$ from the greatest to least. The BG models (Fig. $6 \mathrm{~b}$ to i) can overall simulate well the northward propagation of the precipitation anomalies from tropical areas to subtropical Asia. The GG models (Fig. 6j-o) also can display the northward propagation of precipitation anomalies to a certain extent. However, the propagation patterns are slightly different with that of the observation. The propagation signals in the LG models (Fig. 6p-s) are rather weak, compared to the BG and GG models. Meanwhile, the propagation signals in the LG models are not alike those in the observation.

To show the relationship between intensity anomaly of the SAH and precipitation anomaly over the south and east Asian monsoon regions, we average the simultaneous regression of subseasonal Z100 anomalies on the normalized PC1 over the region of $\left(20^{\circ}-40^{\circ} \mathrm{N}, 35^{\circ}-110^{\circ} \mathrm{E}\right)$ (denoted as $\mathrm{Z} 100{ }^{\mathrm{SAH}}{ }$ ). The same process is done for precipitation anomalies over the region of $\left(20^{\circ}-40^{\circ} \mathrm{N}, 70^{\circ}-120^{\circ} \mathrm{E}\right.$ ) (denoted as $\mathrm{R}_{\text {ASIA }}$ ). Figure 7 displays the scatter diagrams between $\mathrm{Z} 100{ }^{\prime}{ }_{\mathrm{SAH}}$ and $\mathrm{R}_{\text {ASIA }}$ for the observation and 18 models. It is seen that an enhanced SAH is always accompanied by an above-normal precipitation over south and east Asian regions. Furthermore, a quasi-linear relationship is shown between Z100' ${ }_{\mathrm{SAH}}$ and $\mathrm{R}_{\mathrm{ASIA}}$. The correlation coefficient between $\mathrm{Z100}$ ' $\mathrm{SAH}$ and $\mathrm{R}_{\mathrm{ASIA}}$ in BG, GG, and LG group are $0.69,0.61$ and 0.62 , respectively. This result means the stronger (weaker) precipitation is accompanied by the enhanced (damped) SAH. For example, the BG (models showing in Fig. 7 as ' $*$ ') overall reproduces reasonably the enhanced SAH and accompanied positive precipitation anomaly. The GG (showing as 'O') simulate smaller values of positive $\mathrm{Z} 100$ ' and positive $\mathrm{R}_{\text {ASIA }}$ compared to the observation and the BG models. For the LG (showing as '+'), their positive values of Z100' ${ }_{\mathrm{SAH}}$ and R' ASIA are both the smallest.

\section{Mechanism for the subseasonal intensity variation of SAH}

In this section, we diagnose the three dynamical processes contributing to the subseasonal relatively vorticity anomaly at $100 \mathrm{hPa}$ over the SAH's region: horizontal advection of 

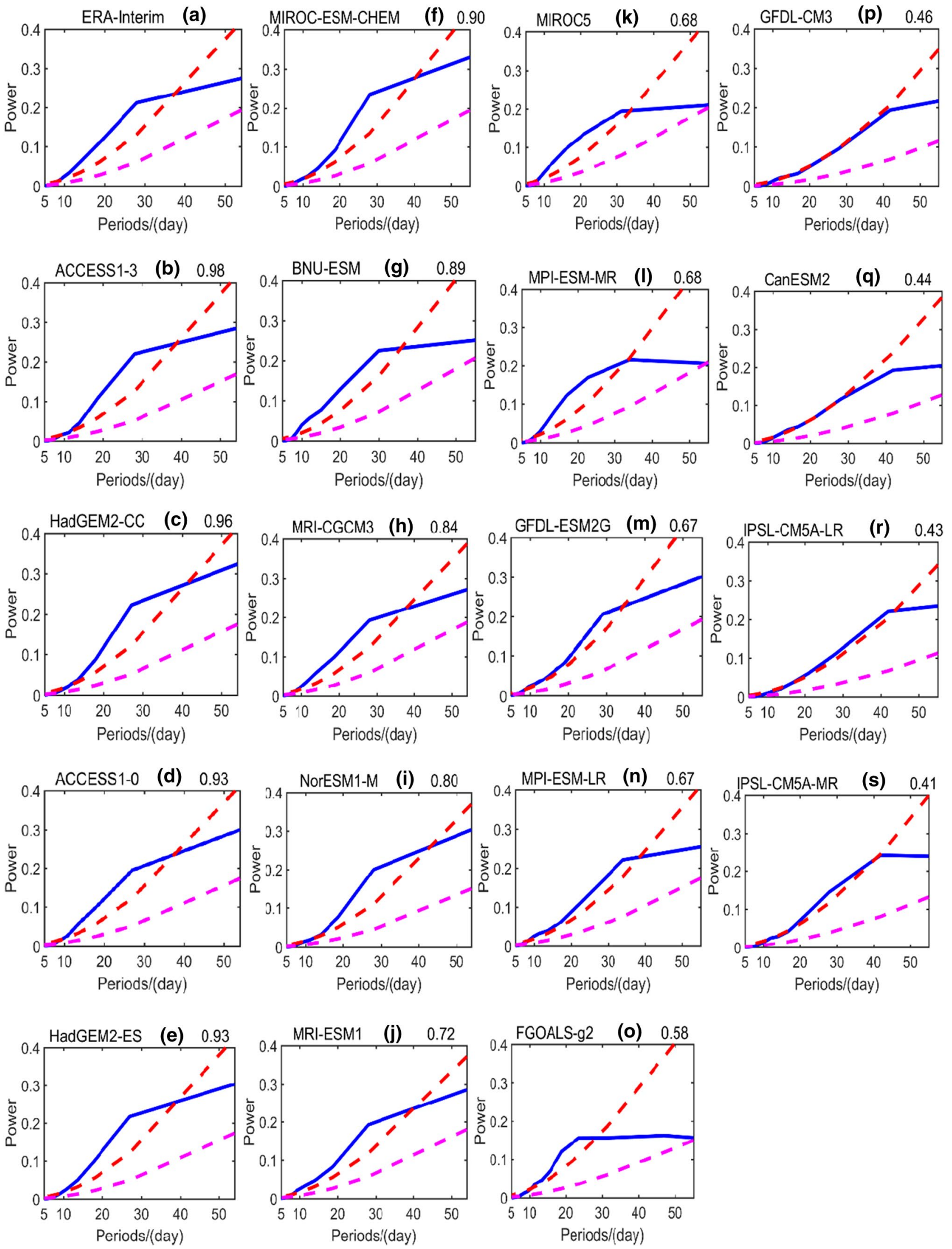
4Fig. 3 The 27-year averaged mean power spectra (blue solid line) of the principal component of the first EOF (PC1) for a ERA-Interim and $\mathbf{b}-\mathbf{s}$ results of the 18 CMIP5 models. The pink dashed line is the red noise spectrum and red dashed line is the spectrum of $95 \%$ confidence level. The values at each of the top-right corners is each models' $r_{\mathrm{EOF}}$. b-s are sorted according to $\mathrm{r}_{\mathrm{EOF}}$ from the greatest to least

relativity vorticity $\left(\frac{\partial \zeta^{\prime}}{\partial t}\right) a d v$, vorticity sources induced by vertical gradients $\left(\frac{\partial \zeta^{\prime}}{\partial t}\right) Q_{1 \_} z$ and by horizontal gradients $\left(\frac{\partial \zeta^{\prime}}{\partial t}\right) S$ of diabatic heating, respectively.

\subsection{The dynamic processes in observation}

Figure $8 \mathrm{a}, \mathrm{b}$ show the latitude-time sections of regressed anomalies in $\left\langle Q_{1}\right\rangle,\left\langle Q_{2}\right\rangle,\left(\frac{\partial \zeta^{\prime}}{\partial t}\right) Q_{1-} z$ at $100 \mathrm{hPa}$ and precipi-

tation against $\mathrm{PC} 1$ averaged over $70^{\circ}-120^{\circ} \mathrm{E}$ for the observation. As mentioned before, a northward propagation of the positive rainfall band can be seen with the strengthening of the SAH. The positive diabatic heating as well as positive moisture sink also propagate from the tropical to the south and east Asian regions. The similar northward propagation of $\left\langle Q_{1}\right\rangle$ and $\left\langle Q_{2}\right\rangle$ anomalies indicates that the anomalous condensational heating induced by the rainfall anomalies dominates the anomalous diabatic heating (Yanai and
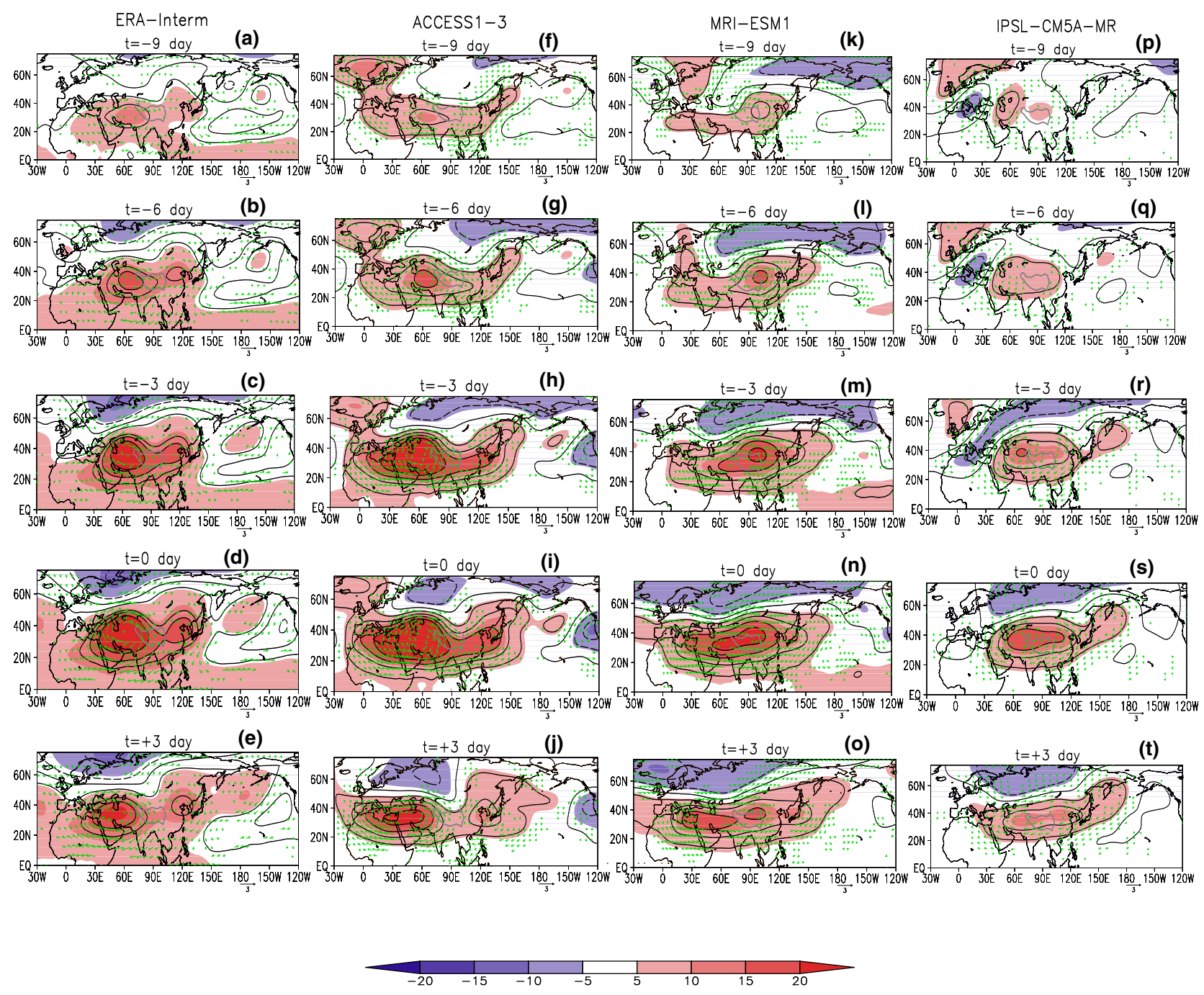

Fig. 4 Regression fields of subseasonal Z100 anomalies (contour with interval of $4 \mathrm{gpm}$ ) and $100 \mathrm{hPa}$ wind field anomalies (vector; $\mathrm{m} \mathrm{s}^{-1}$, only values above the $95 \%$ confidence level are shown) on PC1, from day -9 to day +3 with interval of 3 days, for a-e ERAInterim, f-j ACCESS1-3, k-o MRI-ESM1, and p-t IPSL-CM5A-
MR. The dashed lines denote negative values. The negative (positive) lag days mean Z100 and wind fields anomalies leading (lagging) PC1. Shaded areas denote regions of statistically significant at $95 \%$ confidence level 

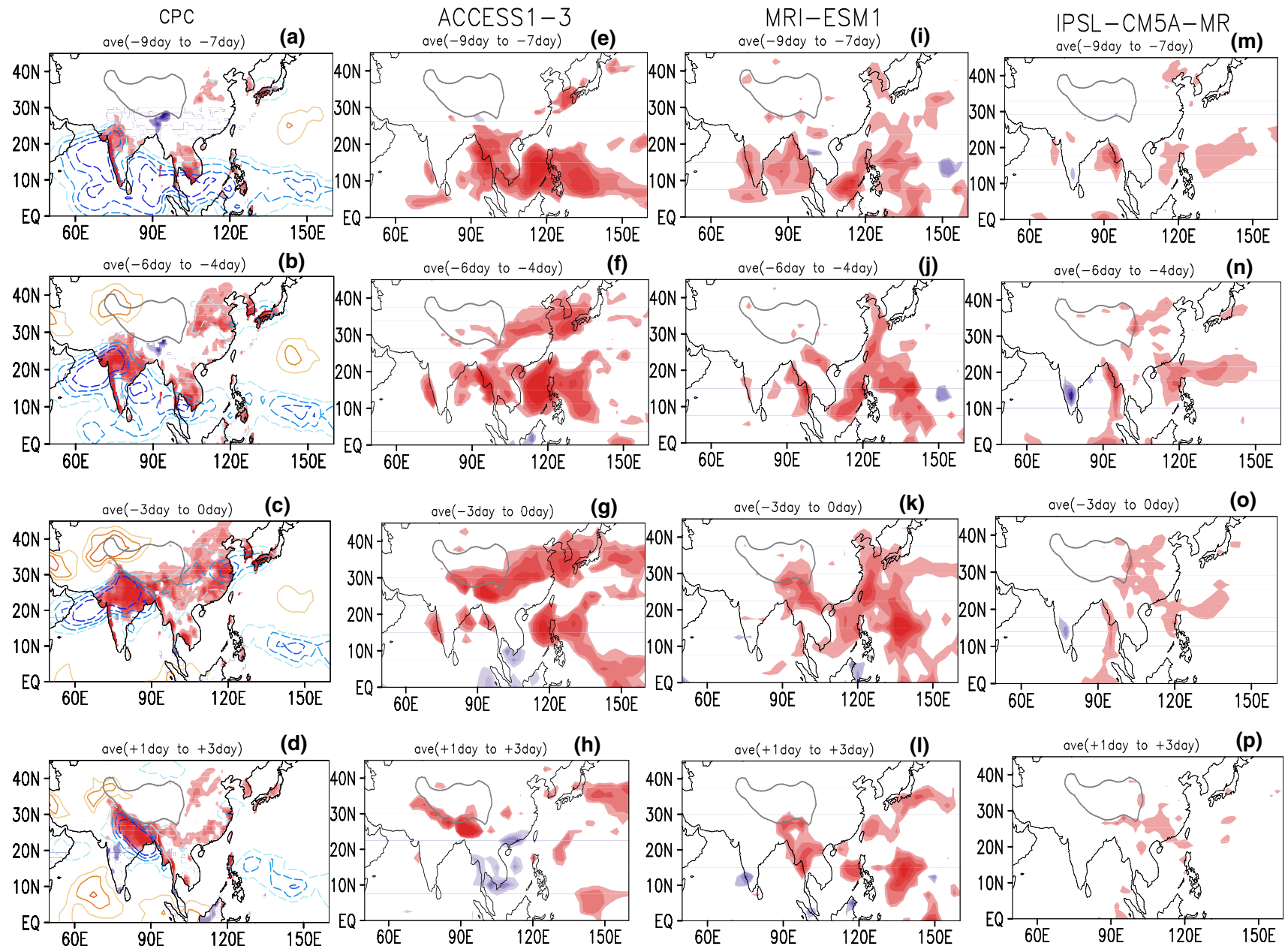

Fig. 5 Regression fields of subseasonal precipitation anomalies (shaded; $\mathrm{mm} \mathrm{d}^{-1}$ ) on $\mathrm{PC} 1$, averaged between days -9 and $-7,-6$ and $-4,-3$ and $0,+1$ and +3 , for a-d the observation (CPC), eh ACCESS1-3, i-l MRI-ESM1, and $\mathbf{m}-\mathbf{p}$ IPSL-CM5A-MR. The

Tomita 1998; Jin et al. 2013). Thus a northward propagation of negative $\left(\frac{\partial \zeta^{\prime}}{\partial t}\right) Q_{1 \_} z$ band is produced in Fig. $8 \mathrm{~b}$ due to the increased vertical gradient of $Q_{1}{ }^{\prime}$ in the upper level. When the negative $\left(\frac{\partial \zeta^{\prime}}{\partial t}\right) Q_{1 \_} z$ band reaches the SAH's main body region, it contributes directly to the strengthening of the SAH. We also used a Linear Baroclinic Model (LBM) experiment to examine the locally responses of circulation to the condensation heating. The results (figure omitted) verify again the effect of condensation heating to the $\mathrm{SAH}$, which is similar to the results showing in Zhang et al. (2016).

The contour in Fig. 8c plots observed regression of $\left(\frac{\partial \zeta^{\prime}}{\partial t}\right) S$. Within the heating region the vertical heating gra- regressed OLR anomalies are plotted by contours in a-d (with interval of $1 \mathrm{~W} \mathrm{~m}^{-2}$ ), with the dashed contours being negative. Shaded areas denote regions of statistically significant at $90 \%$ confidence level

dient dominates the forcing, whereas at the border of the diabatic heating the horizontal heating gradient plays a more important role (Wu and Liu 1998; Liu et al. 2001). In Fig. 8c, on the north flank of the heating, a negative vorticity source which is induced by the horizontal gradient of diabatic heating is generated and propagates northward as well. When the positive rainfall belt propagates northward and reaches around $15^{\circ} \mathrm{N}$ (about day -9), the generated weak negative tendency of vorticity anomalies begins to favor the enhancement of the southern part of SAH. The observed regression of $\left(\frac{\partial \zeta^{\prime}}{\partial t}\right) a d v$, is plotted in Fig. 8d. During the summertime, the climatological easterly flow is located over the southern part of the SAH. It can be seen that the negative vorticity anomalies with the 

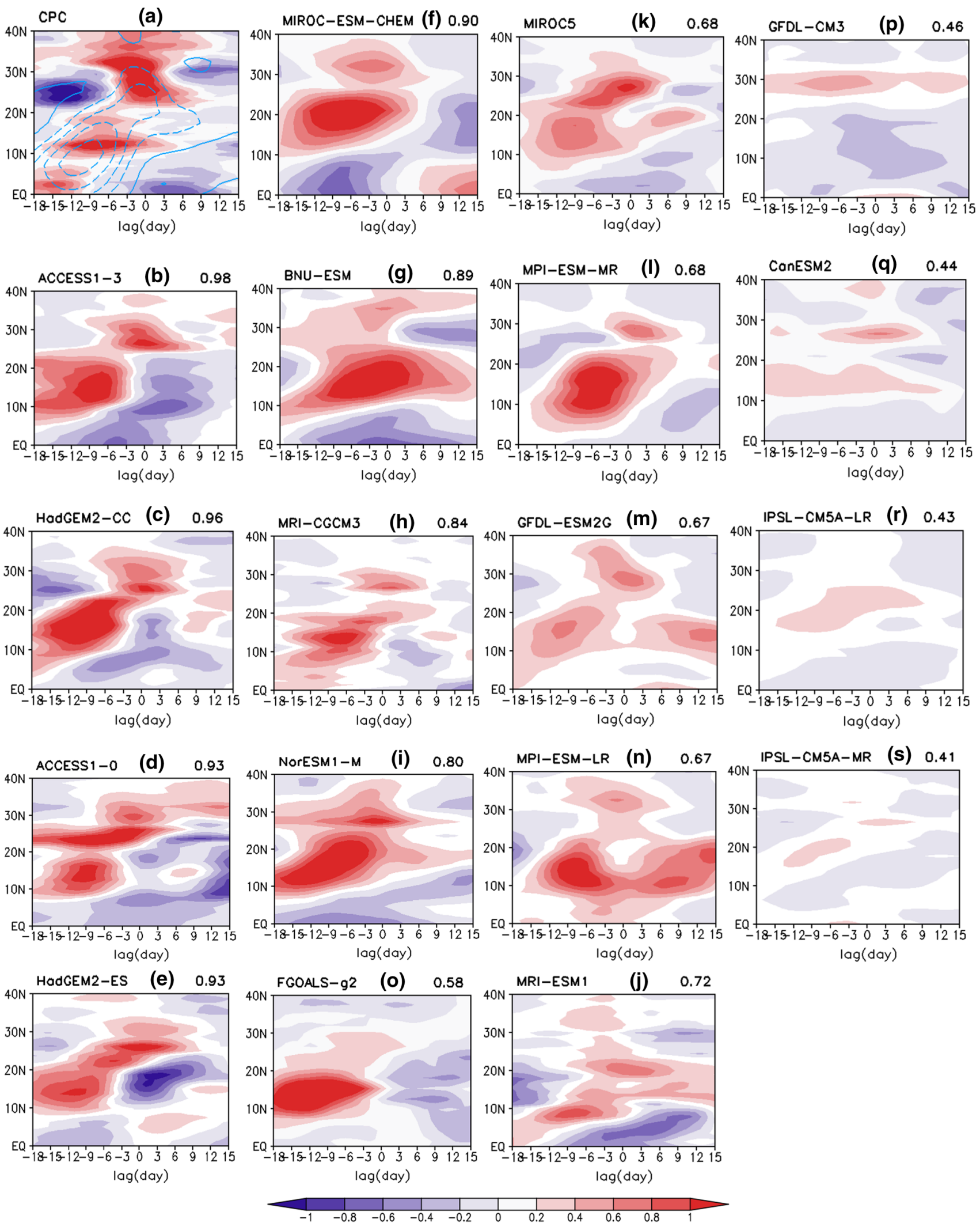

Fig. 6 Lag-regression of subseasonal precipitation anomalies (shaded; $\mathrm{mm} \mathrm{d}^{-1}$ ) on $\mathrm{PC} 1$ averaged over $70^{\circ}-120^{\circ} \mathrm{E}$, for a the observation (CPC) and b-s the 18 CMIP5 models. The values at each of the top-right corners are the same as those in Fig. 3. The regressed observation OLR anomaly is plotted in a (contour; with dashed contour being negative and interval of $1 \mathrm{~W} \mathrm{~m}^{-2}$ ) 


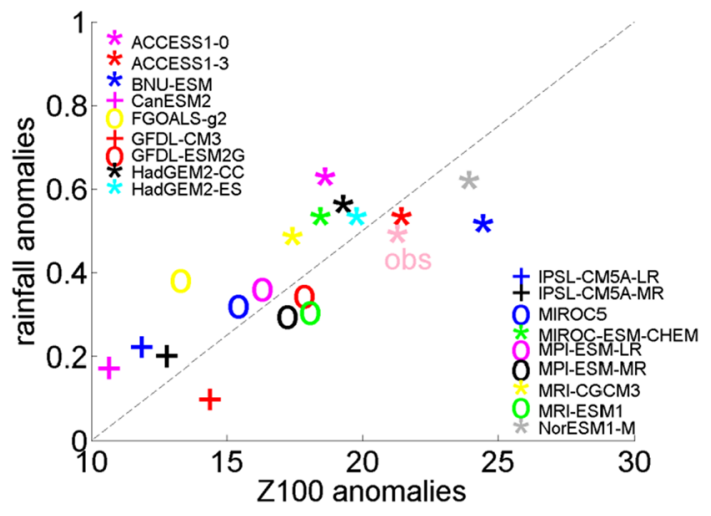

Fig. 7 Scatter diagrams showing the relationship between subseasonal Z100 anomalies (gpm; $\mathrm{x}$-axis) averaged over $20^{\circ}-40^{\circ} \mathrm{N}, 35^{\circ}-$ $110^{\circ} \mathrm{E}$ and precipitation anomalies $\left(\mathrm{mm} \mathrm{d}^{-1} ; \mathrm{y}\right.$-axis) averaged over $20^{\circ}-40^{\circ} \mathrm{N}, 70^{\circ}-120^{\circ} \mathrm{E}$ both at day 0 , for the ERA-Interim and 18 CMIP5 models

climatological easterly flow together induce a westward advection of the negative vorticity, which is conducive to the westward expansion of the SAH.

To demonstrate further the evolutions of above dynamical processes, the three dynamic processes are averaged over the SAH's main body region and plotted in Fig. 9. In the observation, the northward propagating of rainfall band during days -9 to -6 is on the south flank of SAH. Thus, the process of $\left(\frac{\partial \zeta^{\prime}}{\partial t}\right) S$ plays a negative vorticity source in favor of enhancement of the SAH's southern part. The process of $\left(\frac{\partial \zeta^{\prime}}{\partial t}\right) Q_{1 \_} z$ acts to contribute to the enhancement of SAH after day -6. It has the most significant role in the strengthening of SAH around day 0 , when the anomalous rainfall band occupies the south and east Asian regions. The horizontal advection process of $\left(\frac{\partial \zeta^{\prime}}{\partial t}\right) a d v$ is also favorable to the SAH's enhancement, especially during days -6 to days 0 .

\subsection{The models performances}

We next evaluate the selected three models' performances of above dynamical processes. Figure 10 displays the latitude-time sections of regression of simulated subseasonal anomalies of $\left(\frac{\partial \zeta^{\prime}}{\partial t}\right) Q_{1 \_} z,\left(\frac{\partial \zeta^{\prime}}{\partial t}\right) S$ and $\left(\frac{\partial \zeta^{\prime}}{\partial t}\right) a d v$ onto each models' normalized PC1. ACCESS1-3 simulates the northward propagation of negative vorticity tendency generated by $\left(\frac{\partial \zeta^{\prime}}{\partial t}\right) Q_{1 \_} z$ and $\left(\frac{\partial \zeta^{\prime}}{\partial t}\right) S$ (Fig. 10a, b). The simulated westward advection of negative vorticity anomalies is mainly located between $90^{\circ}$ and $120^{\circ} \mathrm{E}$ (Fig. 10c). MRIESM1 reproduces the northward propagation of $\left(\frac{\partial \zeta^{\prime}}{\partial t}\right) Q_{1-} z$ and $\left(\frac{\partial \zeta^{\prime}}{\partial t}\right) S$ in general (Fig. 10d, e). However, the signal is weaker than the observation and ACCESS1-3, due to the weaker simulation of the rainfall band shown in Fig. $6 \mathrm{j}$. The three dynamical processes simulated by IPSL-CM5AMR are rather weak (Fig. 10g-i).

Figure 11 shows the three dynamic processes of the three models averaged over the SAH's main body region. The evolutions and amplitudes of the three area-averaged dynamic processes simulated by ACCESS1-3 resemble those of the observation (Fig. 9). The amplitudes simulated by MRI-ESM1 are weaker compared to the observation and ACCESS 1-3, though the evolutions are similar to the observation. The evolutions of the three dynamic processes simulated by IPSL-CM5A-MR are too weak. Meanwhile, the amplitudes are underestimated dramatically.

\section{Summary and discussion}

The present study investigates the features and dynamical mechanism of the subseasonal intensity variation of SAH at $100 \mathrm{hPa}$ based on the observational data and 18 CMIP5 models during 1979-2005. In the observation, the SAH at $100 \mathrm{hPa}$ is located over the IP-TP and its surrounding areas, with its center value slightly higher than $16,800 \mathrm{gpm}$. An EOF analysis is carried out on the standardized subseasonal $\mathrm{Z} 100$ anomalies over the region of $\left(20^{\circ}-40^{\circ} \mathrm{N}, 35^{\circ}-110^{\circ} \mathrm{E}\right)$. The observed EOF1 pattern demonstrates the strengthening/weakening of the SAH's main body with its center over the IP-western TP region. The intensity variation of SAH displays a periodicity of 10-36-day with the peak around 27-day.

The regressions of the observed anomalies in Z100, $100 \mathrm{hPa}$ wind fields, and precipitation onto the observed normalized PC1 reveal the following features: The SAH's strengthening begins with a weak anomalous high centered over the IP-western TP, and a low poleward of the high located over the Barents Sea and Novaya Zemlya. Above pattern is invigorated gradually and matures on day 0 . Before day -6 , an enhanced rainfall belt migrates northward conspicuously from the equatorial Indian Ocean, the Bay of Bengal, the South China Sea and the Western North Pacific and finally occupies almost the whole Indian subcontinent, Indochina Peninsula and subtropical East Asian regions between $20^{\circ}-40^{\circ} \mathrm{N}$ on day 0 .

Three dynamical processes responsible for the subseasonal intensity variation of SAH are investigated, 
respectively: vertical gradient of diabatic heating $\left(\frac{\partial \zeta^{\prime}}{\partial t}\right) Q_{1-}$, horizontal gradient of diabatic heating $\left(\frac{\partial \zeta^{\prime}}{\partial t}\right) S$, and horizontal advection of relative vorticity $\left(\frac{\partial \zeta^{\prime}}{\partial t}\right) a d v$. The dynamical process of $\left(\frac{\partial \zeta^{\prime}}{\partial t}\right) S$ plays a role in the enhancement of the southern part of SAH around days -9 to -6 due to the horizontal gradient of diabatic heating.
The process of $\left(\frac{\partial \zeta^{\prime}}{\partial t}\right) Q_{1 \_} z$ contributes most significantly to the enhancement of SAH during days -3 to +3 when the anomalous rainfall band occupies $20^{\circ}-40^{\circ} \mathrm{N}$ of the south and east Asian monsoon regions. The horizontal advection process of $\left(\frac{\partial \zeta^{\prime}}{\partial t}\right) a d v$ induces a westward transportation of the negative vorticity, being favorable to the westward expansion of SAH.
Fig. 8 latitude-time section (averaged over $70^{\circ}-120^{\circ} \mathrm{E}$ ) of regressed subseasonal anomalies on PC1 for ERAInterim in a vertically integrated apparent heating source $\left\langle Q_{1}\right\rangle$ (shaded; $\mathrm{W} \mathrm{m}^{-2}$ ) and vertically integrated apparent mositure sink $\left\langle Q_{2}\right\rangle$ (purple contour with interval of $\left.2 \mathrm{~W} \mathrm{~m}^{-2}\right)$; b $\left(\frac{\partial \zeta^{\prime}}{\partial t}\right) Q_{1 \_} z\left(\right.$ shaded; $\left.10^{-11} s^{-2}\right)$ and precipitation (purple contour with interval of $\left.0.2 \mathrm{~mm} \mathrm{~d}^{-1}\right) ; \mathbf{c}\left(\frac{\partial \zeta^{\prime}}{\partial t}\right) Q_{1 \_} z$ (shaded; $10^{-11} s^{-2}$ ) and $\left(\frac{\partial \zeta^{\prime}}{\partial t}\right) S$ (contour with interval of $\left.2 \times 10^{-11} s^{-2}\right)$; d longitude-time section (averaged over $20^{\circ}-35^{\circ} \mathrm{N}$ ) of regressed subseasonal anomalies on PC1 of vorticity advection $\left(\left(\frac{\partial \zeta^{\prime}}{\partial t}\right) a d v\right)$ (shaded; $\left.10^{-11} s^{-2}\right)$
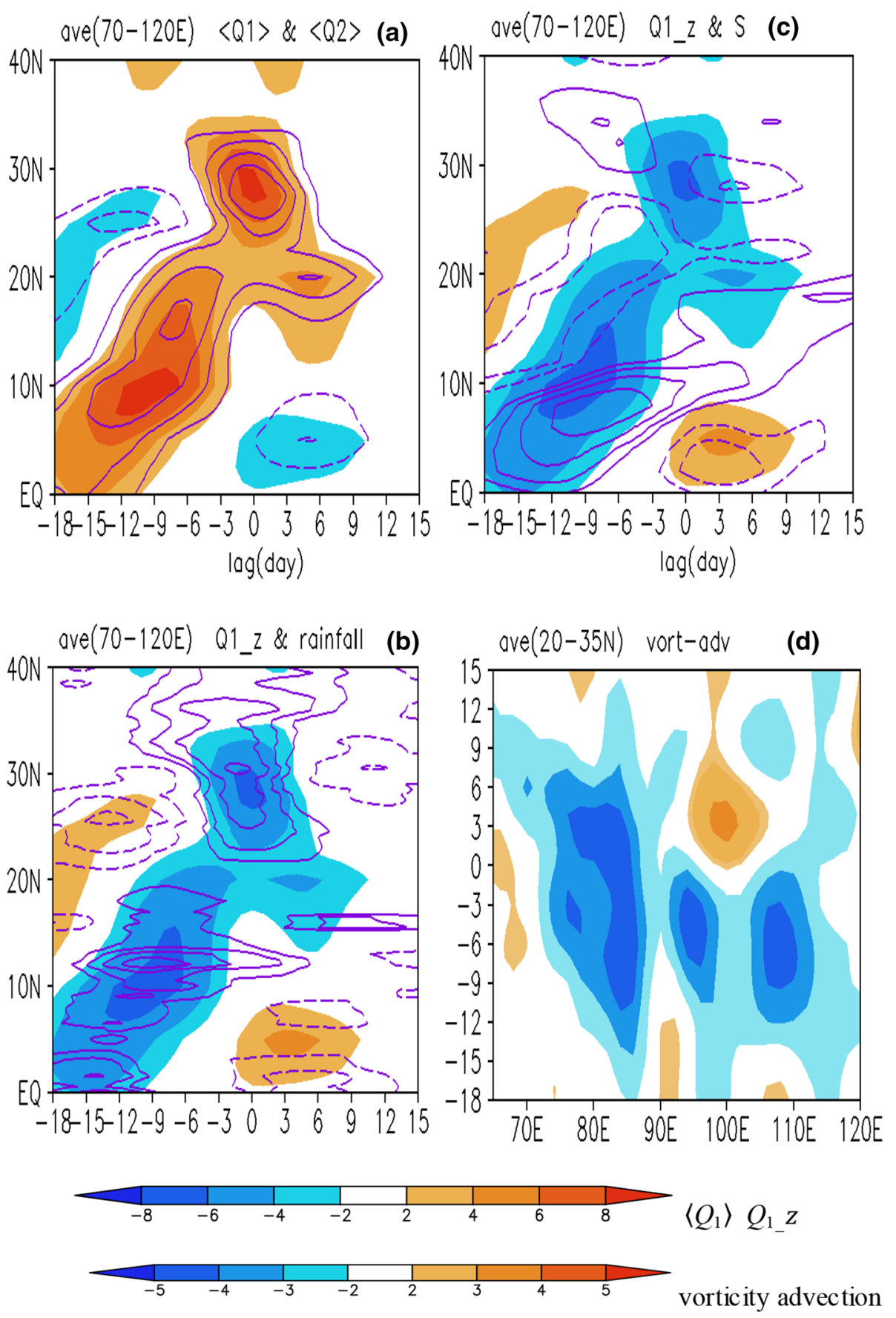


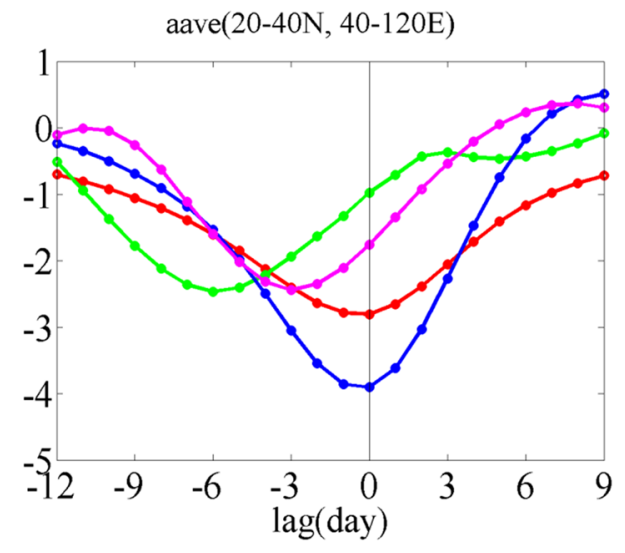

Fig. 9 Regression of observed subseasonal anomalies in $\left(\frac{\partial \zeta^{\prime}}{\partial t}\right) S$ (green line; $\left.10^{-11} s^{-2}\right),\left(\frac{\partial \zeta^{\prime}}{\partial t}\right) a d v$ (purple line; $\left.10^{-11} s^{-2}\right),\left(\frac{\partial \zeta^{\prime}}{\partial t}\right) Q_{1 \_}$ (blue line; $10^{-11} s^{-2}$ ) and $\zeta^{\prime}$ (red line; $10^{-6} s^{-1}$ ) on PC1 averaged over $20^{\circ}-40^{\circ} \mathrm{N}, 40^{\circ}-120^{\circ} \mathrm{E}$

The 18 CMIP5 models capture the zonally elongated structure of the climatological SAH in general. All the 18 CMIP5 models simulate the SAH's monopole pattern of EOF1 to a certain extent. The models are divided into three groups according to the subseasonal pattern correlation coefficient $\left(\mathrm{r}_{\mathrm{EOF}}\right)$ between the observed EOF1 and the models'. One model is selected from each group as their individual representatives: ACCESS1-3 from the BG with $\mathrm{r}_{\mathrm{EOF}}$ above 0.8 , MRI-ESM1 from the GG with $\mathrm{r}_{\mathrm{EOF}}$ between 0.8 and 0.5 , and IPSL-CM5A-MR from the LG with $\mathrm{r}_{\mathrm{EOF}}$ less than 0.5 . ACCESS1-3 (BG) simulates a realistic subseasonal intensity anomaly of SAH. MRI-ESM1 (GG) reproduces a slightly weaker one with the center of anticyclonic anomaly shifting to the western part of TP. IPSL-CM5A-MR (LG) simulates a much weaker one compared to the observation, ACCESS1-3 and MRI-ESM1.

Our results indicate that, the capacity of the 18 models to simulate the SAH's intensity variation has a close conjunction with simulations of the strength as well as the northward propagating features of anomalous rainfall band over the south and east Asian monsoon regions. The realistic simulation of precipitation anomalies in BG models befits reproduction of the dynamical processes related to diabatic heating. When the simulated subseasonal precipitation anomalies (for example, LG models) are too weak and show deficiency in propagating features, the simulated SAH's subseasonal intensity anomalies are dramatically weakened.

The present study shows that the strength and northward propagation of precipitation from the tropics is important
Fig. 10 Upper panels: latitude-time section of regressed subseasonal anomalies in $\left(\frac{\partial \zeta^{\prime}}{\partial t}\right) Q_{1 \_} z\left(10^{-11} \mathrm{~s}^{-2}\right)$ on PC1 averaged over $70^{\circ}$ $120^{\circ} \mathrm{E}$ for a ACCESS1-3, d MRI-ESM1 and g IPSL-CM5A-MR. Middle panels: the same as upper panels, but for $\left(\frac{\partial \zeta^{\prime}}{\partial t}\right) S$. Bottom: the same as upper panels, but for longitude-time section (averaged over $\left.20^{\circ}-35^{\circ} \mathrm{N}\right)$ of regressed subseasonal anomalies in $\left(\frac{\partial \zeta^{\prime}}{\partial t}\right) a d v$

for the reproduction of the subseasonal variation of the SAH. Why some of the models cannot reproduce this northward propagation of precipitation anomalies? Comparison of Figs. 1 and 2, it seems that the model's ability to reproduce subseasonal intensity variation of the SAH has no robust connection with its capacity in simulating the SAH climatology. One of the possible reasons may result from the horizontal resolution of models. In CMIP5, the simulation of precipitation has been further improved to a certain extent compared to the CMIP3. However, the bias of the precipitation simulation is still seen in current general couple models (Chen and Frauenfeld 2014; Yao et al. 2017; Fang et al. 2017). In this paper, it can be found that the top four models in BG models have the same horizontal resolution $(192 \times 144)$, which could be a suitable horizontal resolution for the precipitation simulation related to the SAH subseasonal variation. The lower or higher horizontal resolution can both influence the models performance, which may due to the convective parameterization scheme or microphysis scheme (Giorgi and Marinucci 1996; Chan et al. 2013; Huang et al. 2013; Kan et al. 2015; Yang et al. 2015).

Moreover, the boreal summer intraseasonal oscillation (BSISO) is a dominant signal over the tropical and Asian monsoon region (Yasunari 1979; Krishnamurti and Subramanian 1982; Lau and Chan 1986; Jiang et al. 2004; Annamalai and Sperber 2005; Wang et al. 2005; Lee et al. 2013; Demott et al. 2013). The simulation of large-scale circulation such as mean wind, moisture fields, or western North Pacific subtropical high (WNPSH), and the ocean boundary conditions such as sea surface temperature (SST) could also lead to the bias of models reproduction of northward propagation BSISO signal (Fu and Wang 2004; Park et al. 2009; Levine and Turner 2012; Demott et al. 2013, 2014; Fang et al. 2017), and thus may influence the ability of model to the simulation of SAH variation. The relationship between the subseasonal variations of SAH and the BSISO is not analyzed thoroughly in this study and need a further investigation both in observation and models. More exploration about the above issues should be taken into account in future studies. 
ACCESS1-3
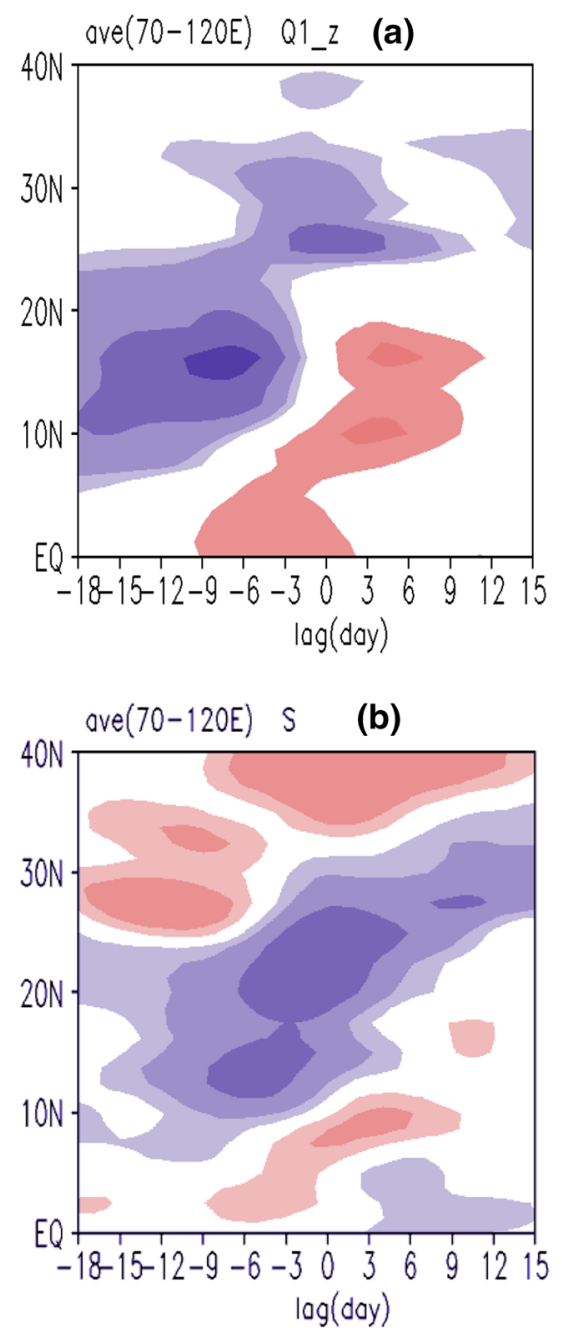

MRI-ESM1
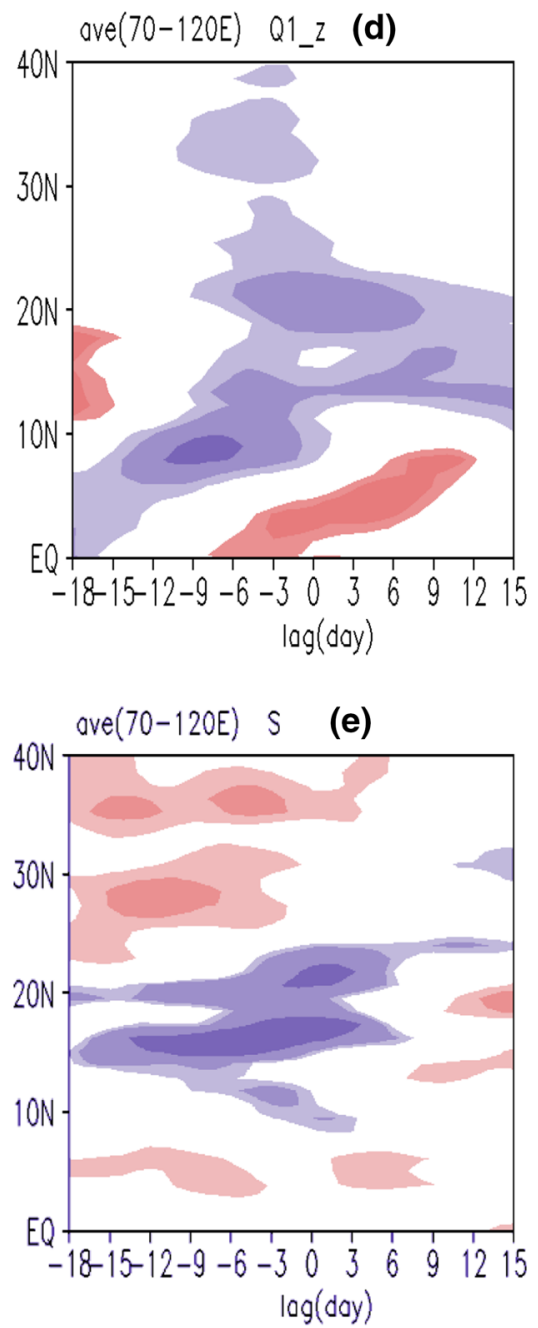

IPSL-CM5A-MR
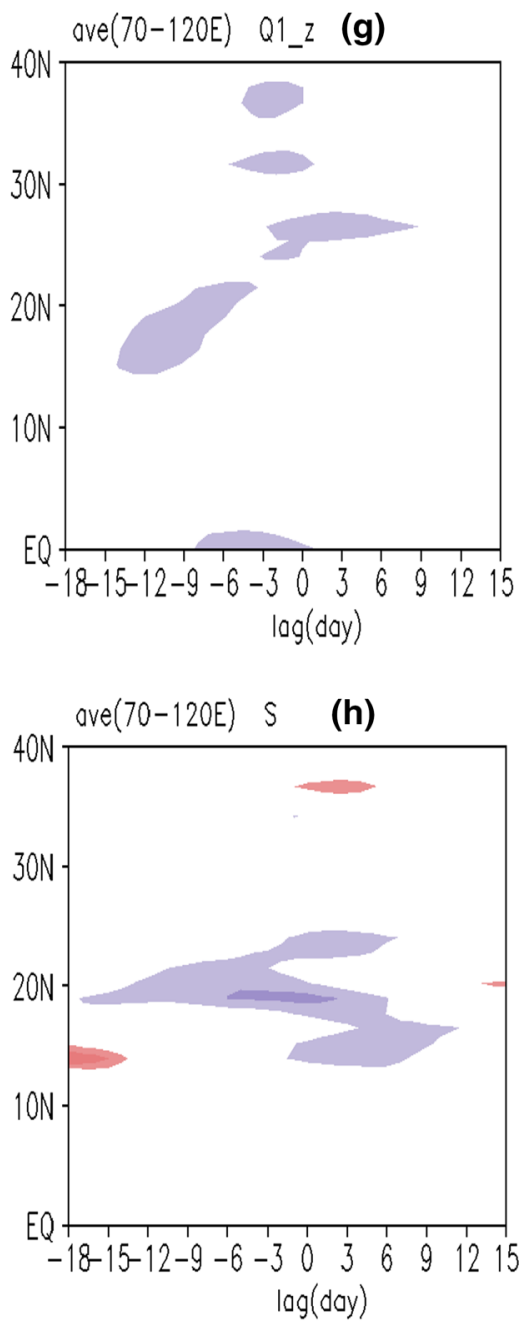
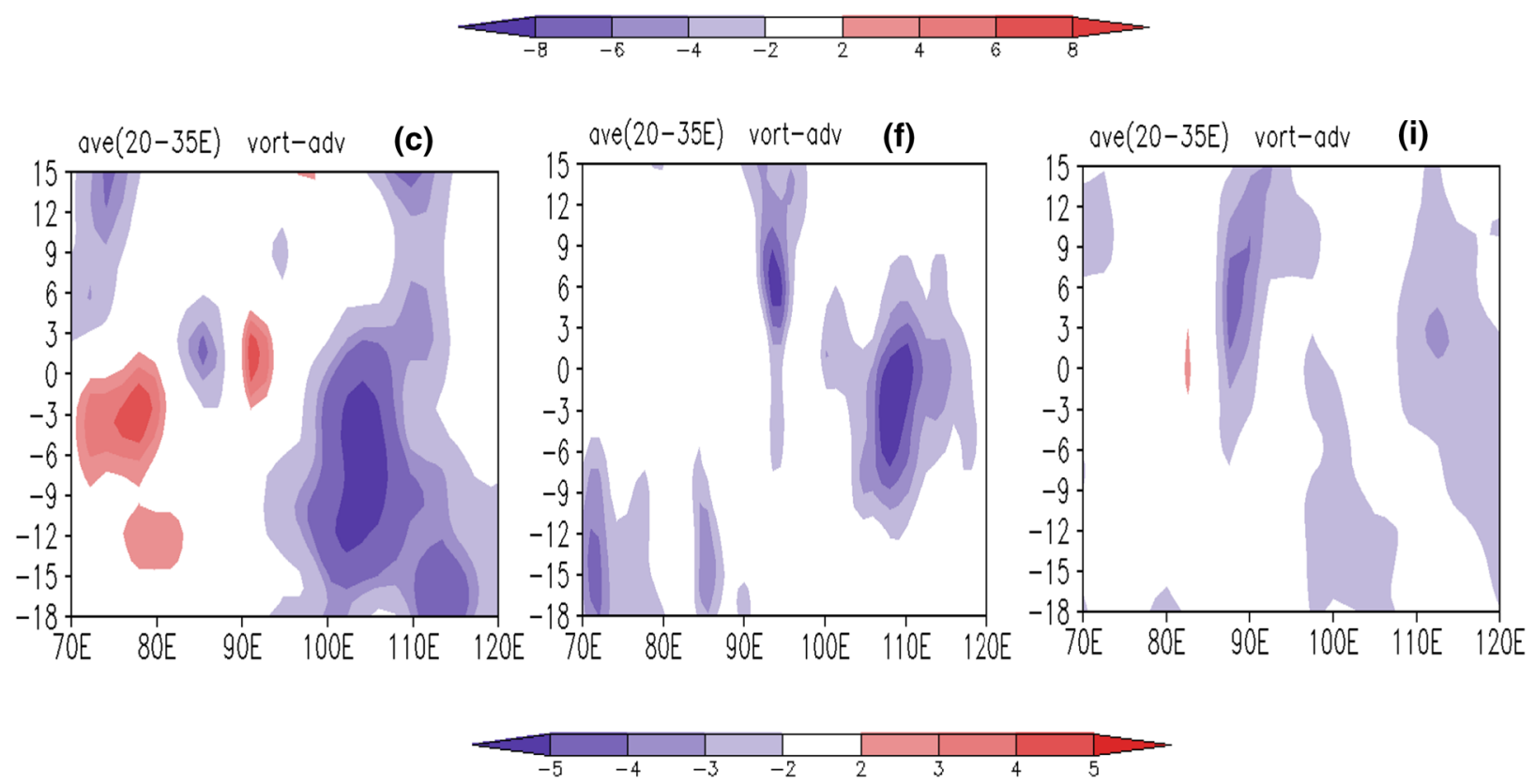


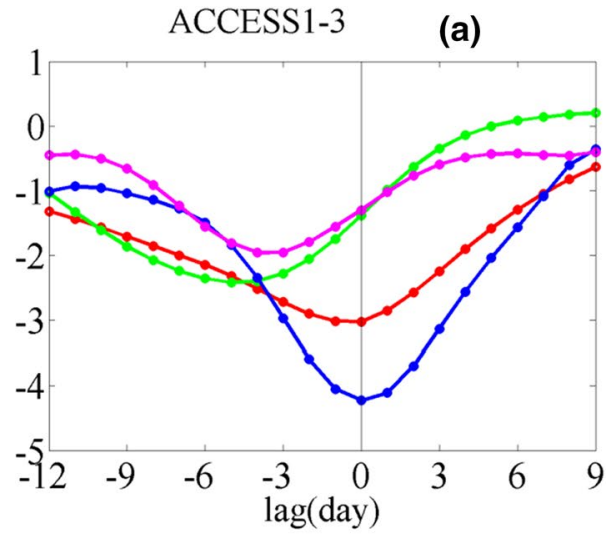

MRI-ESM

(b)

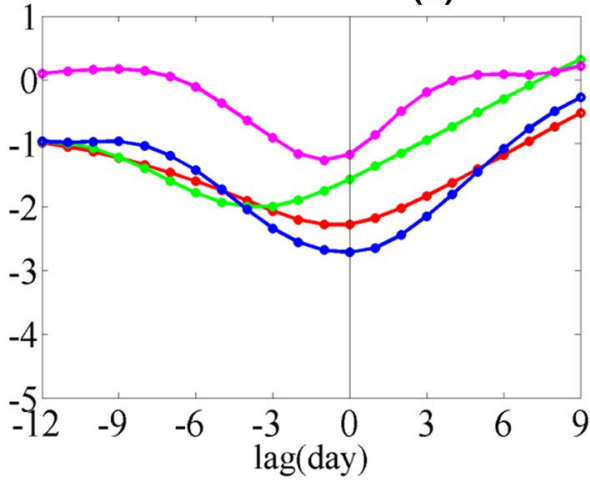

IPSL-CM5A-MR (c)

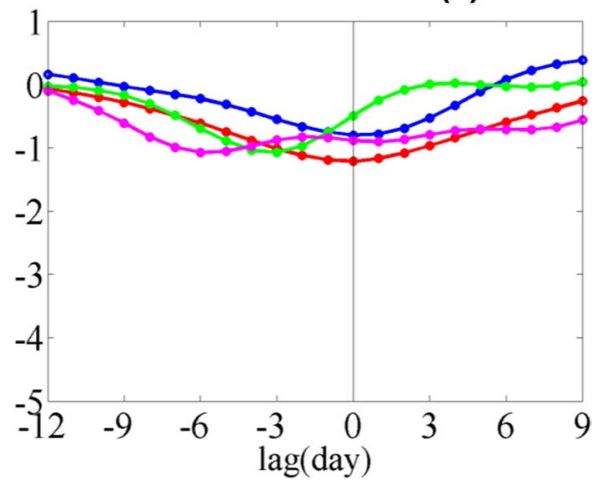

Fig. 11 Regression of subseasonal anomalies in $\left(\frac{\partial \zeta^{\prime}}{\partial t}\right) S$ (green line; $\left.10^{-11} s^{-2}\right),\left(\frac{\partial \zeta^{\prime}}{\partial t}\right) a d v$ (purple line; $\left.10^{-11} s^{-2}\right),\left(\frac{\partial \zeta^{\prime}}{\partial t}\right) Q_{1} z$ (blue line; $10^{-11} s^{-2}$ ) and $\zeta^{\prime}$ (red line; $10^{-6} s^{-1}$ ) on PC1 averaged over $20^{\circ}-$ $40^{\circ} \mathrm{N}, 40^{\circ}-120^{\circ} \mathrm{E}$ for a ACCESS1-3, b MRI-ESM1 and c IPSLCM5A-MR, respectively

Acknowledgements We thank anonymous reviewers for comments and suggestions that have substantially improved the manuscript. This work was jointly supported by the National Natural Science foundation of China under Grants 41621005, 41675067 and 41330420. The ERAInterim daily data is downloaded from http://apps.ecmwf.int/datasets/. The CMIP5 data is available at the Institute of Meteorology at Freie Universität Berlin and German Climate Computing Center (DKRZ). The authors thank Dr. Patricia Margerison for editing the manuscript.
Open Access This article is distributed under the terms of the Creative Commons Attribution 4.0 International License (http://creativeco mmons.org/licenses/by/4.0/), which permits unrestricted use, distribution, and reproduction in any medium, provided you give appropriate credit to the original author(s) and the source, provide a link to the Creative Commons license, and indicate if changes were made.

\section{References}

Annamalai H, Sperber KR (2005) Regional heat sources and the active and break phases of boreal summer intraseasonal (30-50 day) variability. J Atmos Sci 62:2726-2748

Chan SC, Kendon EJ, Fowler HJ, Blenkinsop S, Ferro CAT, Stephenson DB (2013) Dose increasing the spatial resolution of a regional climate model improve the simulatated daily precipitation in a regional climate model? Clim Dyn 41:1475-1495. https://doi. org/10.1007/s00382-012-1568-9

Chen L, Frauenfeld OW (2014) A comprehensive evaluation of precipitation simulations over China based on CMIP5 multimodel ensemble projections. J Geophys Res Atmos 119:5767-5786. https://doi.org/10.1002/2013JD021190

Chen Y, Zhai PM (2016) Mechanisms for concurrent low-latitude circulation anomalies responsible for persistent extreme precipitation in the Yangtze River Valley. Clim Dyn 47:989-1006. https://doi. org/10.1007/s00382-015-2885-6

Chen MY, Shi W, Xie PP, Silva VBS, Kousky VE, Higgins RW, Janowiak JE (2008) Assessing objective techniques for gauge-based analyses of global daily precipitation. J Geophys Res 113:D04110. https://doi.org/10.1029/2007JD009132

Cherchi A, Annamalai H, Masina S, Navarran A (2014) South Asian summer monsoon and the eastern Mediterranean climate: the monsoon-desert mechanism in CMIP5 simulations. J Clim 15:6877-6903. https://doi.org/10.1175/JCLI-D-13-00530.1

Dee DP, Uppala SM, Simmons AJ, Berrisford P, Poli P, Kobayashi S, Andrae U, Balmaseda MA, Balsamo G, Bauer P, Bechtold P (2011) The ERA-Interim reanalysis: configuration and performance of the data assimilation system. Q J R Meteorol Soc 137:553-597. https://doi.org/10.1002/qj.828

Demott CA, Stan C, Randall DA (2013) Northward propagation mechanisms of the Boreal Summer Intraseasonal Oscillation in the ERA-Interim and SP-CCSM. J Clim 26:1973-1992. https:// doi.org/10.1175/JCLI-D-12-00191.1

Demott CA, Stan C, Randall DA, Branson MD (2014) Instraseasonal variation in coupled GCMs: the roles of ocean feedbacks and model physics. J Clim 27:4970-4995. https://doi.org/10.1175/ JCLI-D-13-00760.1

Duan AM, Wu GX (2005) Role of the Tibetan Plateau thermal forcing in the summer climate patterns over subtropical Asia. Clim Dyn 24:793-807. https://doi.org/10.1007/s00382-004-0488-8

Duan AM, Hu J, Xiao ZX (2013) The Tibetan Plateau summer monsoon in the CMIP5 simulations. J Clim 1:7747-7766. https://doi. org/10.1175/JCLI-D-12-00685.1

Ertel H (1942) Ein neuer hydrodynamische wirbdsatz. Metror Z Braunschweig 59:33-49

Fang YJ, Wu PL, Wu TW, Wang ZZ, Zhang L, Liu XW, Xin XG, Huang AN (2017) An evaluation of boreal summer intraseasonal oscillation simulated by BCC_AGCM2.2. Clim Dyn 48:3409-3423. https://doi.org/10.1007/s00382-016-3275-4

Freychet N, Hsu H-H, Chou C, Wu C-H (2015) Asian summer monsoon in CMIP5 project: a link between the change in extreme precipitation and monsoon dynamics. J Clim 15:1477-1493. https://doi.org/10.1175/JCLI-D-14-00449.1 
Fu XH, Wang B (2004) Differences of boreal summer intraseasonal oscillations simulated in an atmosphere-ocean coupled model and an atmosphere-only model. J Clim 17:1263-1271

Gao Y, Wang HJ, Jiang DB (2015) An intercomparison of CMIP5 and CMIP3 models for interannuanl variability of summer precipitation in Pan-Asian monsoon region. Int J Climatol 35:3770-3780. https://doi.org/10.1002/joc.4245

Ge J, You QL, Zhang YQ (2017) The influence of the Asian summer monsoon onset on the northward movement of the South Asian high towards the Tibetan Plateau and its thermodynamic mechanism. Int J Climatol 38:543-553. https://doi.org/10.1002/ joc. 5192

Gilman DL, Fuglister LF, Mitchell JM (1963) On the power spectrum of red noise. J Atmos Sci 20:182-184

Giorgi F, Marinucci MR (1996) Improvements in the simulation of surface climatology over the European region with a nested modeling system. Geophys Res Lett 23:273-276. https://doi. org/10.1029/96GL00050

Hoskins BJ, Mclntyre M, Robertson AW (1985) On the use and significance of isentropic potential vorticity maps. Quart J R Meteor Soc 111:877-946

Huang G, Qu X, Hu KM (2011) The impact of the tropical Indian Ocean on the South Asian high in boreal summer. Adv Atmos Sci 28:421-432. https://doi.org/10.1007/s00376-010-9224-y

Huang D-Q, Zhu J, Zhang Y-C, Huang A-N (2013) Uncertainties on the simulated summer precipitation over Eastern China from the CMIP5 models. J Geophys Res Atmos 118:9035-9047. https:// doi.org/10.1002/jgrd.50695

Jia XL, Yang S (2013) Impact of the quasi-biweekly oscillation over the western North Pacific on East Asian subtropical monsoon during early summer. J Geophys Res Atmos 118:4421-4434. https://doi.org/10.1002/jgrd.50422

Jiang XA, Li T, Wang B (2004) Structures and mechanisms of the northward propagating boreal summer intraseasonal oscillation. J Clim 17:1022-1039

Jiang XW, Li YQ, Yang S, Wu RG (2011) Interannual and interdecadal variations of the South Asian and western Pacific subtropical highs and their relationships with Asian-Pacific summer climate. Meteor Atmos Phys 113:171-180. https://doi.org/10.1007/s0070 3-011-0146-8

Jin FF, Hoskins BJ (1995) The direct response to tropical heating in a baroclinic atmosphere. J Atmos Sci 52:307-319. https://doi. org/10.1175/1520-0469(1995)052,0307:TDRTTH.2.0.CO;2

Jin Q, Yang X-Q, Sun X-G, Fang J-B (2013) East Asian summer monsoon circulation structure controlled by feedback of condensational heating. Clim Dyn 41:1885-1897. https://doi.org/10.1007/ s00382-012-1620-9

Kan MY, Huang AN, Zhao Y, Zhou Y, Yang B, Wu HM (2015) Evaluation of the summer precipitation over the China simulated by BCC_CSM model with different horizontal resolutions during the recent half century. J Geophys Res Atmos 120:4657-4670. https ://doi.org/10.1002/2015JD023131

Krishnamurthy V, Shukla J (2000) Intraseasonal and interannual variability of rainfall over India. J Clim 13:4366-4377. https://doi. org/10.1175/1520-0442(2000)013,0001:IAIVOR.2.0.CO;2

Krishnamurti TN (1973) Tibetan High and upper tropospheric tropical circulation during northern summer. Bull Am Meteorol Soc 54:1234-1249

Krishnamurti TN, Subramanian D (1982) The 30-50 day mode at 850mb during MONEX. J Atmos Sci 39:2088-2095

Lau K-M, Chan PH (1986) Aspects of the 40-50 day oscillation during the northern summer as inferred from outgoing long wave radiation. Mon Weather Rev 114:1354-1367

Lee J-Y, Wang B (2014) Future change of global monsoon in CMIP5. Clim Dyn 42:101-119. https://doi.org/10.1007//s0038 2-012-1564-0
Lee J-Y, Wang B, Wheeler MC, Fu X, Waliser DE, Kang I-S (2013) Real-time multivariate indices for the boreal summer intraseasonal oscillation over the Asian summer monsoon region. Clim Dyn 40:493-509. https://doi.org/10.1007/s00382-012-1544-4

Levine RC, Turner AG (2012) Dependence of Indian monsoon rainfall on moisture fluxed across the Arabian Sea and the impact of coupled mode sea surface temperature biases. Clim Dyn 38:21672190. https://doi.org/10.1007/s00382-011-1096-z doi

Li RQ, Lv SH, Han B, Gao YH, Meng XH (2017) Projections of South Asian summer monsoon precipitation based on 12 CMIP5 models. Int J Climatol 37:94-108. https://doi.org/10.1002/joc.4689

Liebmann B, Smith CA (1996) Description of a complete (interpolated) outgoing longwave radiation dataset. Bull Am Meteorol Soc 77:1275-1277

Lin H (2009) Global extratropical response to diabatic heating variability of the Asian summer monsoon. J Atmos Sci 66:2697-2713. https://doi.org/10.1175/2009JAS3008.1

Liu YM, Wu GX, Liu H, Liu P (2001) Condensation heating of the Asian Summer monsoon and the subtropical anticyclones in the eastern hemispher. Clim Dyn 17:327-338

Liu YM, Wu GX, Ren RC (2004) Relationship between the subtropical anticyclone and diabatic heating. J Clim 17: 682-698. https:// doi.org/10.1175/1520-0442(2004)017,0682:RBTSAA.2.0.CO;2

Liu YM, Hoskins BJ, Blackburn M (2007) Impact of Tibetan orography and heating on the summer flow over Asia. J Meteor Soc Jpn 85B:1-19. https://doi.org/10.2151/jmsj.85B.1

Liu BQ, Wu GX, Mao JY, He JH (2013) Genesis of the South Asian high and its impact on the Asian summer monsoon onset. J Clim 26:2976-2991. https://doi.org/10.1175/JCLI-D-12-00286.1

Luo HB, Yanai M (1984) The large-scale circulation and heat sources over the Tibetan Plateau and surrounding areas during the early summer of 1979. Part II: heat and moisture budgets. Mon Weather Rev 112:966-989

Mason RB, Anderson CE (1963) The development and decay of the 100-mb summertime anticyclone over southern Asia. Mon Weather Rev 91:3-12. https://doi.org/10.1175/15200493(1963)091,0003:TDADOT.2.3.CO;2

Park S, Hong S-Y, Byun Y-H (2009) Precipitation in boreal summer simulated by a GCM with two convective parameterization schemes: implications of the Intraseasonal Ocsillation for dynamic seasonal predicition. J Clim 23:2801-2816. https://doi. org/10.1175/2010JCLI3283.1

Qu X, Huang G (2012) An enhanced influenced of tropical Indian Ocean on the South Asian high after the late 1970s. J Clim 25:6930-6941. https://doi.org/10.1175/JCLI-D-11-00696.1

Qu X, Huang G (2015) The decadal variability of the tropical Indian Ocean SST-the South Asian High relation: CMIP5 model study. Clim Dyn 45:273-289. https://doi.org/10.1007/S0038 2-014-2285-3

Randel WJ, Park M (2006) Deep convective influence on the Asian summer monsoon anticyclone and associated tracer variability observed with Atmospheric Infrared Sounder (AIRS). J Geophys Res 111:271-273. https://doi.org/10.1029/2005JD006490 D12314

Ren XJ, Yang DJ, Yang X-Q (2015) Characteristics and mechanisms of the subseasonal eastward extension of the South Asian high. J Clim 28:6799-6822. https://doi.org/10.1175/JCLI-D-14-00682.1

Shi J, Qian WH (2016) Connection between anomalous zonal activities of the South Asian high and Eurasian summer climate anomalies. J Clim 15:8249-8267. https://doi.org/10.1175/JCLI-D-15-0823.1

Sooraj KP, Terray P, Xavier P (2016) Sub-seasonal behavior of Asian summer monsoon under a changing climate: assessments using CMIP5 models. Clim Dyn 46:4003-4025. https://doi.org/10.1007/ s00382-015-2817-5

Tao SY, Zhu FK (1964) The 100-mb flow patterns in southern Asia in summer and its relation to the advance and retreat of the 
West-Pacific subtropical anticyclone over the far east. Acta Meteorol Sin 34:385-396 (in Chinese)

Taylor K, Stouffer R, Meehl G (2012) An overview of CMIP5 and experiments design. Bull Am Meteor Soc 93:485-498. https:// doi.org/10.1175/BAMS-D-11-00094.1

Wang LJ, Ge J (2016) Relationship between low-frequency oscillations of atmospheric heat source over the Tibetan Plateau and longitudinal oscillations of the South Asia high in the summer. Chin J Atmos Sci 40(4):853-863. https://doi.org/10.3878/j.issn.10069895.1509 .15164 (in Chinese)

Wang B, Webster PJ, Teng H (2005) Antecedents and self-induction of the active-break Indian summer monsoon. Geophys Res Lett 32:L04704. https://doi.org/10.1029/2004GL020996

Wei W, Zhang RH, Wen M, Rong XY, Li T (2014) Impact of Indian summer monsoon on the South Asian high and its influence on summer rainfall over China. Clim Dyn 43:1257-1269. https://doi. org/10.1007/s00382-013-1938-y

Wu GX, Liu HZ (1998) Vertical vorticity development owing to down-sliding at slantwise isentropic surface. Dyn Atmos Oceans 27:715-743

Wu GX, Liu YM, Liu P (1999) The effect of spatially nonuniform heating on the formation and variation of subtropical high. Part I: scale analysis. Acta Meteorol Sin 57:257-263 (in Chinese)

Wu GX, He B, Liu YM, Bao Q, Ren RC (2015) Location and variation of the summertime upper-troposphere temperature maximum over South Asia. Clim Dyn 45:2757-2774. https://doi.org/10.1007/ s00382-015-2506-4

Xie PP, Yatagai A, Chen MY, Hayasaka T, Fukushima Y, Liu CM, Yang S (2007) A gauge-based analysis of daily precipitation over East Asia. J Hydrometeor 8:607-627. https://doi.org/10.1175/ JHM583.1

Xue X, Chen W, Chen SF (2017) The climatology and interannual variability of the South Asian high and its relationship with ENSO in CMIP5 models. Clim Dyn 48:3507-3528. https://doi.org/10.1007/ s00382-016-3281-6

Yanai M, Tomita T (1998) Seasonal and interannual variability of atmospheric heat sources and moisture sinks as determined from NCEP-NCAR reanalysis. J Clim 11:463-482

Yanai M, Esbensen S, Chu J-H (1973) Determination of bulk properties of tropical cloud clusters from large-scale heat and moisture budgets. J Atmos Sci 30: 611-627. https://doi.org/10.1175/15200442(1998)011,0463:SAIVOA.2.0.CO;2
Yang SY, Li T (2016) Zonal shift of the South Asian High on subseasonal timescale and its relation to the summer rainfall anomaly in China. Quart J R Meteor Soc 142:2324-2335. https://doi. org/10.1002/qj.2826

Yang J, Qing B, Wang B, Gong D-Y, He H, Gao M-N (2014) Distinct quasi-biweekly features of the subtropical East Asian monsoon during early and late summer. Clim Dyn 42:1469-1486. https:// doi.org/10.1007/s00382-013-1728-6

Yang B, Zhang YC, Qian Y, Wu TW, Huang AN, Fang YJ (2015) Parametric sensitivity analysis for the Asian summer monsoon precipitation simulation in the Beijing Climate Center AGCM, version 2.1. J Clim 28:5622-5644. https://doi.org/10.1175/JCLID-14-00655.1

Yang J, Qing B, Wang B, He HZ, Gao MN, Gong DY (2017) Characterizing two types of transient intraseasonal oscillations in the Eastern Tibetan Plateau summer rainfall. Clim Dyn 48:1749_ 1768. https://doi.org/10.1007/s00382-016-3170-z

Yao JC, Zhou TJ, Guo Z, Chen XL, Zou LW, Sun Y (2017) Improved performance of high-resolution tropospheric models in simulating the East-Asian summer monsoon rainbelt. J Clim 30:8825-8840. https://doi.org/10.1175/JCLI-D-16-0372.1

Yasunari T (1979) Cloudiness fluctuations associated with the northern hemisphere summer monsoon. J Meteor Soc Jpn 57:227-242

Zarrin A, Ghaemi H, Azadi M, Farajzadeh M (2010) The spatial pattern of summertime subtropical anticyclones over Asia and Africa: a climatological review. Int J Climatol 30:159-173. https ://doi.org/10.1002/joc.1879

Zhang CD, Ling J (2012) Potential vorticity of the Madden-Julian oscillation. J Amos Sci 69:65-78. https://doi.org/10.1175/ JAS-D-11-081.1

Zhang Q, Wu GX, Qian YF (2002) The bimodality of the $100 \mathrm{hPa}$ South Asia high and its relationship to the climate anomaly over East Asia in summer. J Meteor Soc Jpn 80:733-744

Zhang PQ, Yang S, Kousky VE (2005) South Asian high and AsianPacific-American climate teleconnection. Adv Atmos Sci 22:915923. https://doi.org/10.1007/BF02918690

Zhang PF, Liu YM, He B (2016) Impact of East Asian summer monsoon heating on the interannual variation of the South Asian high. J Clim 29:159-173. https://doi.org/10.1175/JCLI-D-15-0118.1 